\title{
DISTANT COMPLIANCE WITH TREATMENT IN PATIENTS WITH CHRONIC RESPIRATORY DISEASES: ASTHMA, COPD AND ASTHMA-COPD OVERLAP SYNDROME. PROSPECTIVE STUDY
}

\author{
Simona Maria Jîrcă $\breve{1}^{1,2}$, Marius Sorin Ciontea ${ }^{3}$, Elena Vlad ${ }^{4}$, Florin Dumitru Mihălţan ${ }^{5}$ \\ ${ }^{1}$ Târgu Jiu County Emergency Hospital, Allergology and Clinical Immunology Department, \\ Târgu Jiu, Romania \\ ${ }^{2}$ Carol Davila" University of Medicine and Pharmacy, BI. Eroii Sanitari, nr. 8, sector 5, \\ Bucharest, Romania \\ "Tudor Vladimirescu" Pneumology Hospital, Runcu, Gorj, Romania \\ ${ }^{4}$ Târgu Jiu County Emergency Hospital, Pneumology Department, Târgu Jiu, Romania \\ 5" Marius Nasta" Institute of Pneumology, Bucharest, Romania \\ Corresponding author: \\ Simona Maria Tîrcă, Allergology and Clinical Immunology Speciality, PhD student at "Carol \\ Davila" University of Medicine and Pharmacy, specialist physician, Târgu Jiu County \\ Emergency Hospital, Str. Victoriei, nr 196, Târgu Jiu \\ simonanistorescu@gmail.com
}

\begin{abstract}
Medications prescribed for chronic diseases such as asthma, chronic obstructive pulmonary disease (COPD) or asthma-COPD overlap (ACO) syndrome should be administered in the long term and compliance becomes a health care concern. Noncompliance adversely affects the outcome of treatment and results in the consumption of human and material resources. The aim of our study was to identify the factors that cause non-compliance with treatment in children, adolescents, and adults with asthma/COPD/ACO in Romania, the methods by which these factors can be understood and corrected, and the evaluation of symptoms. To achieve the goal, regular visits were carried out with symptom control questionnaires (Asthma Control Test (ACT), COPD Assessment Test (CAT)) and FEV1 evaluation using spirometry. The results obtained indicate low long-term compliance (12.35\%) due to patients' abstinence from regular check-ups. In conclusion, we can say that the factors related to doctors have been successfully corrected, but it remains a challenge in correcting the factors related to patients and the health regime.
\end{abstract}

Keywords: compliance, noncompliance factors, asthma, COPD. 


\section{INTERNAL}

\section{Original Papers}

\section{Rezumat}

Medicamentele prescrise pentru bolile cronice precum astmul, boala pulmonară obstructivă cronică (BPOC) sau sindromul overlap astm-BPOC (sindrom ACO) trebuie administrate pe termen lung, iar complianţa devine o preocupare în domeniul îngrijirii sănătății. Noncomplianța afectează negativ rezultatul tratamentului și determină consum de resurse umane și materiale. Scopul studiului nostru a fost identificarea factorilor care cauzează noncomplianța la tratament la copii, adolescenți și adulți cu astm/BPOC/ACO din România, metodele prin care acești factori pot fi înțeleși și corectați și evaluarea simptomelor. Pentru îndeplinirea scopului au fost efectuate vizite periodice cu realizarea de chestionare privind controlul simptomelor (Testul de Control al Astmului - ACT, Testul de Evaluare a BPOC - CAT) și evaluarea FEV1 cu ajutorul spirometriei. Rezultatele obținute indică o complianță pe termen lung scăzută (12,35\%) din cauza absenteismului pacienților la controalele periodice. În concluzie putem afirma că au fost corectați cu succes factorii ce depind de medici, dar corectarea factorilor ce țin de pacienți și regimul sanitar rămâne o provocare.

Cuvinte cheie: complianță, factori noncomplianță, astm, BPOC.

\section{Introduction}

Due to the fact that prescribed medications should be taken in the long term, compliance becomes a health care concern. Noncompliance adversely affects the outcome of treatment and results in the consumption of resources.

This study addresses the modality to determine the distant compliance related to chronic respiratory diseases via periodic patient follow-up and the evaluation of symptom control. In addition, our goal is to identify the factors that cause noncompliance with treatment in children, adolescents and adults with asthma / COPD (chronic obstructive pulmonary disease) / ACO (asthma-COPD overlap) syndrome in Romania, and how the issues can be assessed, understood and corrected. Compliance with medications is essential to prevent exacerbations and to improve the control of respiratory symptoms.

Unfortunately, not all patients observe the treatment regimen and it is difficult for clinicians to estimate their compliance, as 
there is currently no simple and accurate method to help assess it. We, the doctors, need to find methods to address the lack of compliance and other issues related to poor control of asthma, COPD and ACO. In this study we consider patient-related factors, including demographic factors such as age, sex, and disease severity.

\section{Basic definitions: compliance, adherence, noncompliance}

Compliance represents the degree to which patients follow clinicians' recommendations and has adverse implications on patient autonomy and clinician-patient relationship ${ }^{(1)}$.

The term compliance is defined as "consenting" or "doing as you are told"(2). Compliance is "an intentional and responsible process of care, in which patients and physicians strive together to achieve each other's health goals“(3).

Adherence is described by the International Society for Pharmacoeconomics and Outcomes Research (ISPOR) as "the extent to which a patient acts in accordance with the prescribed interval and dose of a dosing regimen" ${ }^{(4)}$. Adherence, used as a substitute for compliance, puts the therapeutic relationship into its appropriate perspective, focusing on the patient's participation in treatment choice decisions and being nonjudgmental about the patient's medicationtaking behaviour ${ }^{(1)}$.

Noncompliance is defined as failure to observe the recommended treatment. It can be interpreted as the inability to follow instructions. It can take many forms and can be the result of very different underlying causes. Identifying the reasons for noncompliance is essential for determining the appropriate intervention strategy ${ }^{(5)}$.
Noncompliance with medications of patients with asthma /COPD /ACO may worsen the disease, may require a change in regular therapy, may increase the number of hospitalizations and increase the costs of care services. Many patients with asthma or COPD continue to have poorly controlled disease due to poor compliance with therapy. The costs for asthma treatments vary widely from country to country; in Europe we can estimate an average cost per patient per year, including all forms of asthma (intermittent, mild, moderate and severe asthma) of $\$ 1,900^{(6)}$ and in the US an estimated average cost per patient per year of $\$ 3,100^{(7,8)}$. Centers for Disease Control and Prevention estimate allocated costs for COPD of $\$ 32.1$ billion in 2010 , with a projected growth to $\$ 49.0$ billion by 2020 . Total costs of absenteeism were $\$ 3.9$ billion in 2010 , with 16.4 million working days lost due to $\operatorname{COPD}^{(9)}$. The United States is the largest health care consumer in the world, with total health costs of \$ 1.6 trillion in 2002. DeMatteo estimated that on more than 188 million medical visits patients do not follow the doctor's advice, suggesting cost increases of more than \$ 300 billion a year. Using national health statistics, Iskedjian et al. estimated that hospitalization costs attributed to patient noncompliance with control therapy in Canada exceeded \$ 1.6 billion $^{(10)}$.

The World Health Organization classifies the reasons for noncompliance with treatment according to the category of patient, health status, medication, socio-economic conditions, low level of education, health system or medical team and the treatment itself $^{(11)}$. A study conducted on 71 patients in Romania revealed that noncompliance with treatment represents $13.6 \%{ }^{(12)}$. It is estimated that the prevalence of COPD in Romania is $9.3 \%{ }^{(13)} /(8.3 \%$ in 2018 versus $8.13 \%$ in $2012)^{(14)}$ and $5-7 \%$ subjects with asthma and it 


\section{INTERNAL}

\section{Original Papers}

is increasing ${ }^{(15)}$. The INSPIRO Study estimates that approximately 200,000 people in Romania have COPD ${ }^{(16)}$.

\section{Objectives of the study}

The main objectives of the study were to reveal and correct noncompliance factors and to describe the prevalence of distant compliance. The secondary objectives of the study were to assess the severity of symptoms in patients with COPD, asthma and ACO and the therapeutic response using spirometry (evaluation / improvement of FEV1).

Compliance is multifactorial and is being affected by patients (health beliefs, cognitive abilities, environmental factors, comorbidities), physicians (physician-patient relationship, time, device training, patient communication), and the health system (Table 1).

\section{Specific strategies adopted to correct noncompliance}

Once the noncompliance factors were identified, we developed an algorithm to correct them. Despite the correction of most of the noncompliance factors presented, the results show that the low compliance is directly related to factors associated with the patient and the regimen. Factors related to the medical environment were completely corrected, but factors such as psychosocial, socio-economic, cultural and religious issues, patient's level of knowledge and education could not be changed. The factors related to the regimen could not be improved either.

\section{a. Guidelines for the correction of noncompliance factors in asthma}

The therapeutic strategy in asthma is undoubtedly individualized in each country, it is carried out according to socio-economic conditions, national strategy and health policy.

Currently, we have resorted to the following strategies to correct compliance factors:

- planned asthma visits. At each visit we provided feedback to increase patient confidence and we observed the appointment schedule.

- Triggers (allergens, smoking) were revealed and their avoidance was recommended. They have been evaluated to prevent exacerbations and loss of asthma control.

- The treatment plan was developed and a written plan was made. The importance of using the medication, even in the absence of symptoms, was discussed with the patient and the therapeutic response was verified. Patients were informed about the status of the disease and the consequences of not observing the treatment. 


\begin{tabular}{|c|c|c|}
\hline Patient related factors & $\begin{array}{l}\text { Regimen } \\
\text { related } \\
\text { factors }\end{array}$ & $\begin{array}{l}\text { Doctor related } \\
\text { factors }\end{array}$ \\
\hline $\begin{array}{l}\text { Psychosocial, socio-economic, cultural and } \\
\text { religious problems }\end{array}$ & $\begin{array}{l}\text { medication } \\
\text { costs }\end{array}$ & $\begin{array}{l}\text { quality of the medical } \\
\text { services }\end{array}$ \\
\hline The level of patient education & $\begin{array}{l}\text { Complicated } \\
\text { work schedules }\end{array}$ & $\begin{array}{l}\text { doctor-patient } \\
\text { cooperation, }\end{array}$ \\
\hline Age & & $\begin{array}{l}\text { lack of } \\
\text { communication with } \\
\text { the patient, }\end{array}$ \\
\hline $\begin{array}{l}\text { Various patient perceptions about the disease } \\
\text { and medications. Antipathy towards } \\
\text { medication. Fears about side effects and fear } \\
\text { of addiction }\end{array}$ & & $\begin{array}{l}\text { lack of explanations } \\
\text { for using the device }\end{array}$ \\
\hline $\begin{array}{l}\text { Failure to comply with the chronic nature of } \\
\text { asthma }\end{array}$ & & \\
\hline $\begin{array}{l}\text { Underestimation of severity due to lack of } \\
\text { symptoms. }\end{array}$ & & \\
\hline $\begin{array}{l}\text { Difficulties in handling the device (inhalation } \\
\text { technique) }\end{array}$ & & \\
\hline Comorbidity (combination of several drugs). & & \\
\hline depression, anxiety & & \\
\hline Care for other family members & & \\
\hline Forgetfulness & & \\
\hline Self-interruption & & \\
\hline
\end{tabular}

Table 1. Noncompliance factors in the studied population 


\section{INTERNAL}

\section{Original Papers}

- The inhalation technique was theoretically and practically explained to each patient. Subsequently, each patient received a demo device which they could practice the inhalation technique with in order to better master it.

- Regarding the concrete strategy for asthma control, the Asthma Control Test (ACT) questionnaire was used, which provides a standardized way to capture the necessary information about the disease. In parallel, spirometry was also performed.

- A good doctor-patient relationship was maintained. The physician's communication skills were used to motivate patients and strengthen progress.

- Leaflets with information on asthma and inhalation techniques were provided.

- It was recommended to avoid the administration of beta-blockers, the administration of aspirin to those with the Samter's triad (aspirin sensitivity) and sulphites in patients with a previous history.

- A gastroenterologist visit was recommended for the treatment of gastrointestinal disorders: gastroesophageal reflux and gastritis b. Guidelines for the correction of noncompliance factors in COPD

- COPD visits were planned, observing appointments and providing feedback at each visit.

- Extrinsic factors (tobacco smoking, air pollution, occupational or environmental exposure - the latter being caused by burning biomass fuels) and infections were revealed and we recommended avoiding them.

- The treatment plan was developed and a written plan was made. The importance of using the medication, the status of the disease and the consequences of not observing the treatment even in the absence of symptoms were discussed with the patient.

- Each patient was shown the inhalation technique, then each patient was given a demo device where they could practice the inhalation technique in order to better master it.

- The CAT questionnaire - the COPD assessment test which provides information on the control of COPD was used. Lung function was also assessed using spirometry.

- A good doctor-patient professional relationship was maintained and the doctor's communication skills were used to motivate patients and consolidate progress. 
- Information leaflets on COPD and inhalation techniques were provided.

- The regimen has been simplified to increase compliance.

\section{Materials and methods}

\section{Subjects included in the study}

This is a prospective randomized clinical study conducted in 3 centres in 2 towns ( $\mathrm{Tg}$ Jiu and Timisoara), on the compliance of patients with asthma, COPD and ACO in the Romanian population. This study was conducted after the written consent of the participating patients, 251 subjects from rural and urban settings. Enrolment started in January 2017 and lasted until March 2019. A questionnaire on symptom control was applied to each patient

\section{Patients included in the study:}

- Age $>6$ and under 80

- Patients with an initial and previous diagnosis of asthma, COPD or ACO were included.

\section{Exclusion criteria include:}

- Age below 6 and above 80

- Any acute or chronic condition that would have limited patients' ability to fill in the questionnaires

\section{Clinical and paraclinical data}

The therapeutic response was evaluated in all the patients in the study via paraclinical investigations of lung function using spirometry (FEV1 follow-up).

Asthma was confirmed based on clinical criteria (wheezing, shortness of breath, chest tightness and cough varying in time and intensity) along with spirometry showing variable limitation of expiratory airflow (reversibility after bronchodilator (BD) testing)): increase in FEV $1>12 \%$ and $>200$ $\mathrm{ml}$ from baseline 10-15 minutes after administration of SABA (short-acting beta2agonist) $200-400 \mathrm{mcg}$ ). Patients with asthma stage 1-5 GINA were selected according to their treatment needs.

The selection of patients with chronic obstructive pulmonary disease (COPD) was performed based on respiratory criteria (persistent respiratory symptoms - dyspnoea chronic cough or sputum production, wheezing, chest tightness) and paraclinical spirometry. Patients with COPD had a postbronchodilator forced expiratory volume in 1 s / forced vital capacity (FEV1 / FVC) $<0.7$ without reversibility after bronchodilator (SABA).

Patients with asthma-COPD overlap (ACO) have persistent limitation of airflow with several characteristics; it is identified in clinical practice by the characteristics it shares with both asthma and COPD.

Lifestyle data (smoker status, exposure to toxins, atopic terrain) and personal medical history were obtained by the physician. Nonsmokers, former smokers or current smokers were included in the study. Regarding the smoking status, subjects were classified as non-smokers (people who have never smoked) and smokers (daily smokers or people who occasionally smoked more than one cigarette per day, at any time in their lives). The associated personal pathological history and their involvement in the respiratory condition were followed. Atopic patients have been allergologically evaluated by performing skin prick tests with environmental aeroallergens, animal epithelia, dust mites and moulds.

\section{Study design}

Distant compliance in patients with asthma, COPD and ACO in Romania was a prospective randomized clinical study conducted in 3 hospitals in the country. Patients were 


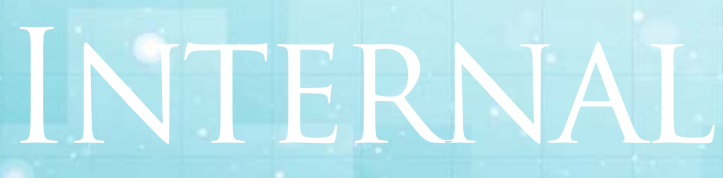

Original Papers

recruited by pulmonologists and allergists in hospitals. Patients with asthma, COPD and ACO who met the eligibility criteria were identified in each site and invited to participate in the study. The study considered following the patient over a year; no additional interventions or procedures were required beyond clinical practice. Each patient completed a self-report questionnaire (ACT for asthma, CAT for COPD) to identify symptoms. Patients with ACO completed both questionnaires.

At the study visit, doctors collected the following information: socio-demographic, comorbidities, current treatment of COPD, asthma and ACO, spirometry, number of exacerbations and self-report questionnaires. An exacerbation was defined as an acute worsening of respiratory symptoms that led to additional therapy, for example, bronchodilators, bronchodilators plus antibiotics and/or oral corticosteroids or requiring hospitalization or emergency department visits $^{(17)}$. Information was collected during interviews with patients. The indices of CAT and ACT questionnaires were calculated and the evaluation of FEV1 using spirometry. Patients with asthma taking long-term control medications were classified according to the severity of symptoms as intermittent, mild, persistent, moderate, or severe, and patients already receiving treatment were classified as: controlled, partially controlled, or uncontrolled, according to National Asthma Education and Prevention Program (NAEPP) recommendations $^{(18)}$. COPD patients were classified in groups I to IV according to GOLD recommendations $^{(19)}$. The study and the informed consent form were approved by the Ethics Committee. All patients provided their written consent prior to enrolment.

\section{Assessments}

Study participants completed questionnaires at each visit. Health status and symptomatic impact of COPD were determined using the COPD Assessment Test [CAT] ${ }^{(20)}$, with scores between 0 and 40, where higher scores indicate poorer health (Table 2).

Asthma symptoms were assessed using the Asthma Control Test (ACT) questionnaire, which includes four symptom / reliever questions, plus a self-assessed level of patient control, where higher scores indicate better health. The interpretation of the ACT score is: ACT score 20-25 =asthma is fully controlled, score 16-19 = asthma is partially controlled, situation in which it is necessary to change the treatment to obtain a total control, and a score between 5-15 indicates uncontrolled asthma ${ }^{(5)}$.

The ACT and CAT questionnaires were used to collect patients' responses regarding symptom control. During the study visit, the investigators assessed the control of patients' symptoms according to the value of the 


\begin{tabular}{|l|l|l|}
\hline $\begin{array}{l}\text { CAT } \\
\text { score }\end{array}$ & Level & Clinical significance \\
\hline$>30$ & Very high & Daily activities are affected \\
\hline$>20$ & High & $\begin{array}{l}\text { Dyspnoea occurs even during the lightest activities or even when } \\
\text { the patients speak. All activities require a great deal of effort. }\end{array}$ \\
\hline $10-20$ & Medium & $\begin{array}{l}\text { Just a few days per week are good. Presents one or two } \\
\text { exacerbations per year. Activities are done very slowly, with } \\
\text { frequent breaks. }\end{array}$ \\
\hline$<10$ & Low & $\begin{array}{l}\text { Most days are good and the symptoms worsen with intense } \\
\text { physical activity. }\end{array}$ \\
\hline
\end{tabular}

Table 2. Clinical significance of CAT score

\begin{tabular}{|c|c|}
\hline Characteristics & Patients(N?=251) \\
\hline $\begin{array}{l}\text { Sex } \mathrm{n}(\%) \\
\quad \text { Women } \\
\text { Men }\end{array}$ & $\begin{array}{l}46 \\
54\end{array}$ \\
\hline \begin{tabular}{ll} 
& \multicolumn{2}{l}{ Origin $\mathrm{n}(\%)$} \\
- & urban \\
& rural \\
\end{tabular} & $\begin{array}{l}50.6 \\
49.4 \\
\end{array}$ \\
\hline 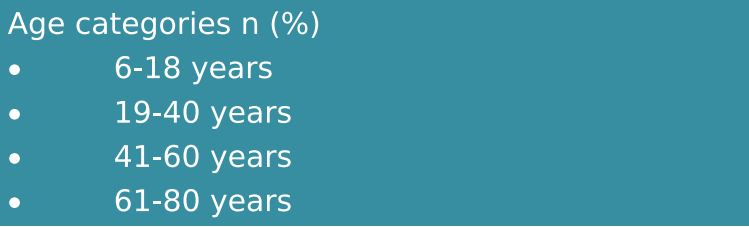 & $\begin{array}{l}12.5 \\
17 \\
45 \\
25.5\end{array}$ \\
\hline $\begin{array}{l}\text { Living conditions } \mathrm{n}(\%) \\
\text { - } \quad \text { active smokers } \\
\text { - } \quad \text { non-smokers } \\
\text { - } \quad \text { ex-smokers }\end{array}$ & $\begin{array}{l}15.6 \\
71.2 \\
13.2\end{array}$ \\
\hline Personal pathological history (comorbidities), no. & 148 \\
\hline $\begin{array}{l}\text { Prick skin testing } \mathrm{n}(\%) \\
\text { - } \quad \text { negative } \\
\text { - } \quad \text { allergic sensitization } \\
\text { - } \quad \text { dermographism } \\
\text { - } \quad \text { not tested } \\
\end{array}$ & $\begin{array}{l}17 \\
34 \\
2 \\
47\end{array}$ \\
\hline Exacerbations over a period of one year, n (\%) & 4.78 \\
\hline $\begin{array}{l}\text { Patient compliance } \mathrm{n}(\%) \\
\text { - } \quad \text { compliant } \\
\text { - } \quad \text { partially compliant } \\
\text { - } \quad \text { noncompliant }\end{array}$ & $\begin{array}{l}52.6 \\
35 \\
12.4\end{array}$ \\
\hline
\end{tabular}

Table 3. Clinical and demographic characteristics of the study patients FEV1 / FVC post-bronchodilator forced expiratory volume in $1 \mathrm{~s} /$ forced vital capacity, OVD obstructive ventilatory dysfunction, RLD Restrictive lung disease, MVD mixed ventilatory defect 


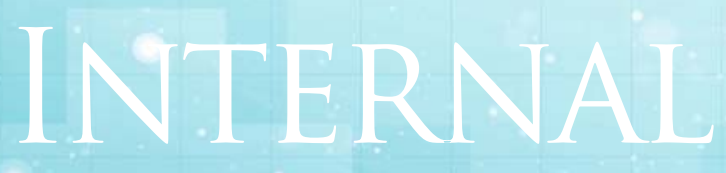

Original Papers

questionnaire and spirometry. Patients were followed over a period of one year and classified as compliant (those who had 5 visits within a year), partially compliant (those who did not observe the control periods and had between 2-4 visits) or noncompliant (those who did not show up at any control at all). Compliance assessment was associated with observing the patient reassessment visits.

\section{Results}

\section{Patients' characteristics}

A total of 265 patients were enrolled in the study. Out of these, 14 patients did not meet all eligibility criteria and were excluded, while 251 patients were included in the final analysis. The demographic and clinical characteristics of the studied population are presented in Table 3. 54\% of the patients were male. Demographics were largely similar between the sexes.

In total, $12.4 \%$ of the patients had 5 visits during the year; $35 \%$ were partially compliant and $52.6 \%$ were noncompliant. Compliance was assessed by the number of visits, assessment of symptoms using the ACT questionnaire and performing spirometry. The following comorbidities were more common: confirmed CV disease $25.2 \%$, hypertension $20.8 \%$, metabolic diseases, including diabetes $8.4 \%$, confirmed anxiety and depression 2\% (Figure 1). All patients
(100\%) received treatment for asthma, COPD and $\mathrm{ACO}$ at the time of the enrolment and several treatment patterns were identified (tablets, inhalers). The treatment varied at each visit depending on the symptoms and in order to obtain the best compliance. The use of emergency medication has been reduced by the improvement of the symptoms. A total of $5.2 \%$ of patients reported using rescue medication at the first visit and only $0.4 \%$ at the last visit. At the first visit, $7.56 \%$ of the patients aged between 6 and 18 received treatment with tablets, and $30.6 \%$ of the people aged between 41 and 60 received inhalation therapy.

The prevalence of the inhaler use at the age of $41-60$ was $8.36 \%$ and decreased at visit 3 , where the administration of tablets of $4.38 \%$ predominates in the first age category. At visit 4 , the prevalence of tablet treatment in the first age group maintained a similar distribution (3.6\%) with the administration of inhalation therapy associated with tablets in the 41-60 age group. At visit 5, the administration of inhalation treatment predominates, $1.99 \%$ in the age category between 61-80 (Figure 2).

COPD symptoms were assessed using the $A C T$ questionnaire for COPD. The prevalence of the symptoms maintained a similar distribution and increased with the severity of COPD, based on airflow obstruction. A total of $8.8 \%$ of patients from group 3 and $8.4 \%$ from 


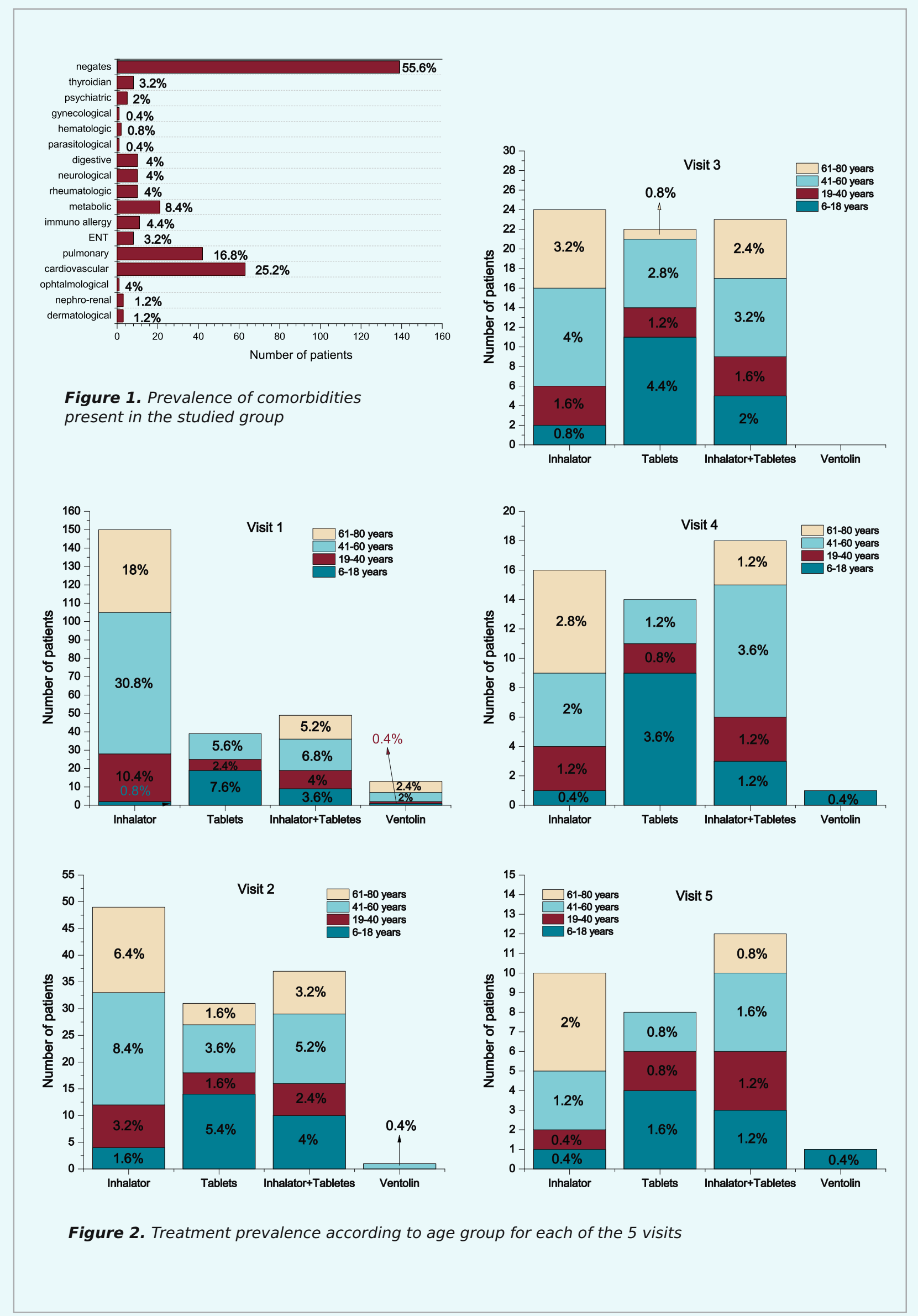




\section{Original Papers}
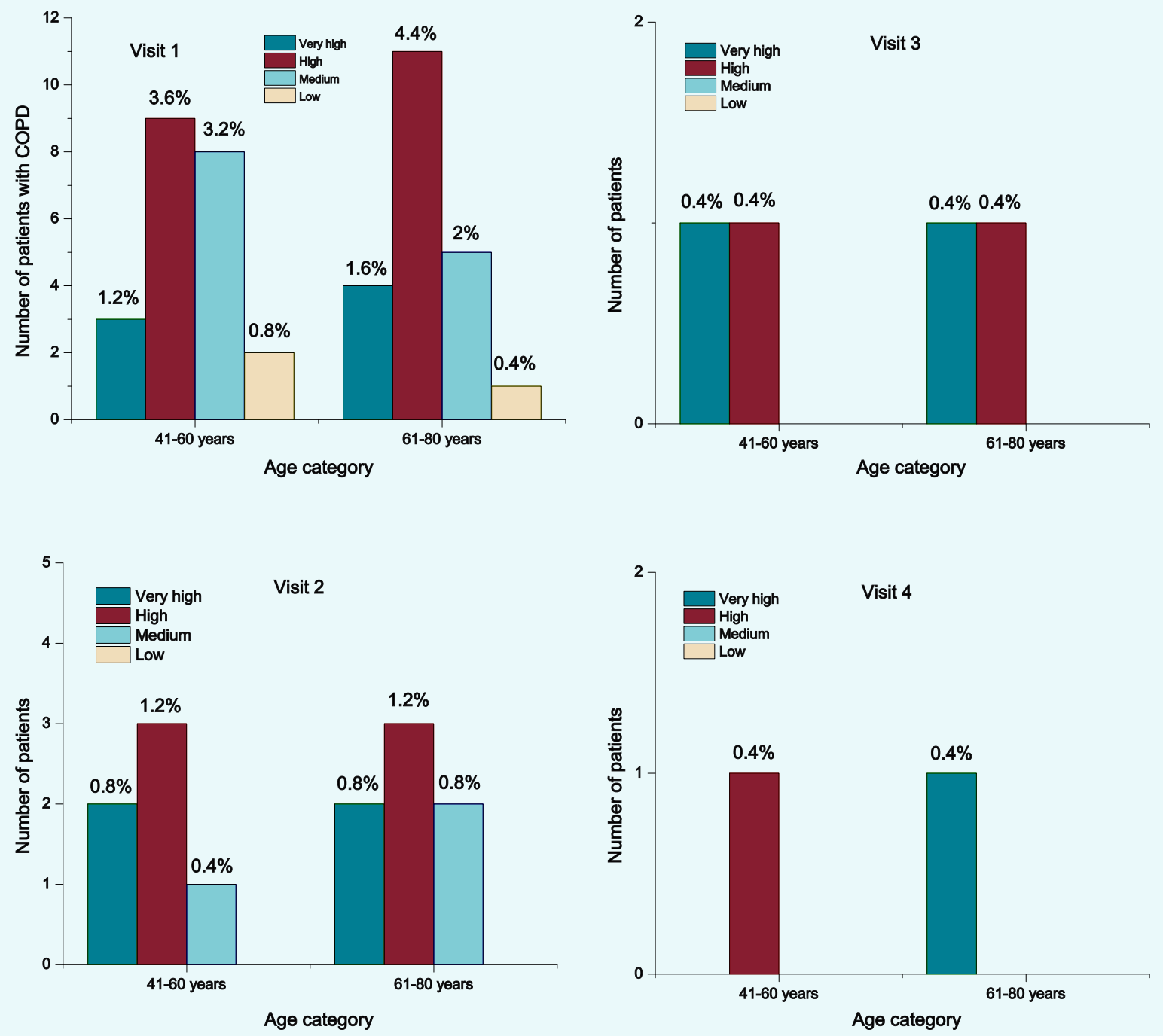

Figure 3. The prevalence of the individual respiratory symptoms in COPD patients and their severity at each visit 


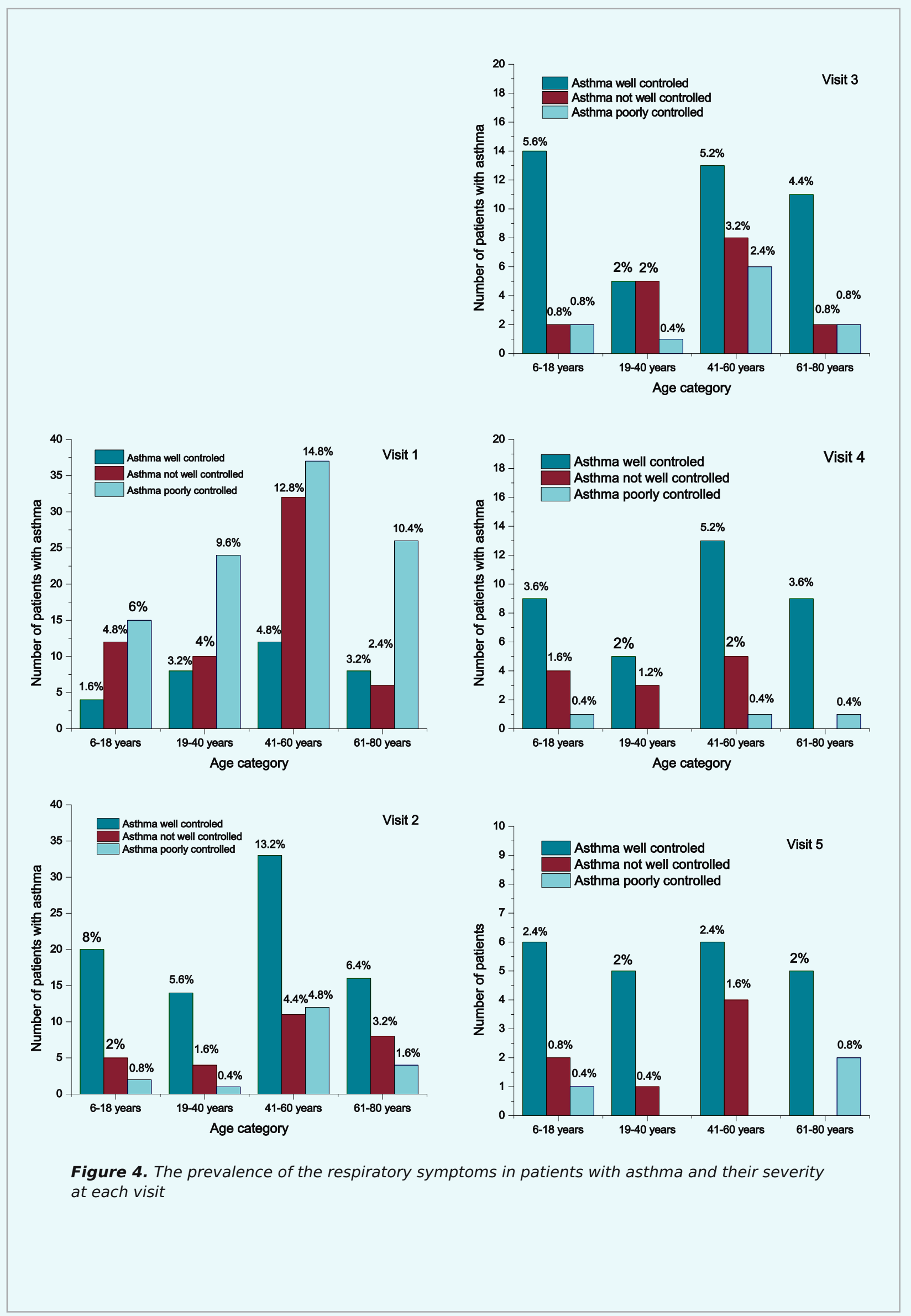




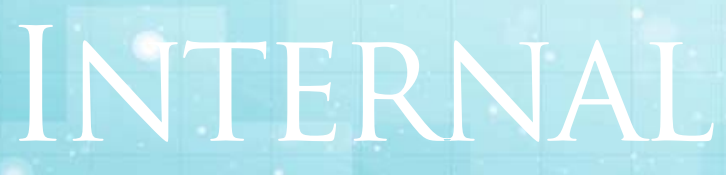

Original Papers

group 4 had symptoms of COPD, where high ACT predominated $(3.6 \%$ and $4.4 \%$, respectively); the visits of COPD patients decrease, at visit 4 reaching to be only $0.4 \%$ ACT with a high level and $0.4 \%$ ACT with very high level, reporting the lack of control of symptoms. None of the COPD patients had 5 visits (Figure 3 ). For each combination of symptoms, a significant association between these and lung function was described ( $p$ $<0.001$ for all).

The prevalence of asthma symptoms and their severity were assessed using the CAT questionnaire. The prevalence of the symptoms maintained a similar distribution and increased with the severity of the asthma. Regardless of the age category, there is an improvement in asthma control. If during the first visit uncontrolled or partially controlled asthma predominates (in the 6-18 age group $4.8 \%$ have partially controlled asthma; in the 19-40 group age $9.6 \%$ have uncontrolled asthma and $4 \%$ have partially controlled asthma; patients with age between 41-60 $12.8 \%$ have partially controlled asthma and $14.8 \%$ had uncontrolled asthma; and in the 61-80 age group $10.4 \%$ have uncontrolled asthma), during the following visits asthma is better controlled, so at visit 5 controlled asthma predominates with $8.8 \%$, partially controlled asthma $2.8 \%$, and uncontrolled asthma is found in only $1.2 \%$ of the patients (Figure 4 ).
The clinical status of the patients presented in Figure 5 had individual variations. The clinical examination was evaluated in a group of only 149 patients. Despite the treatment, some patients continued to have sibilant rales, bronchial rales or both. It should be noted that most of the patients had a normal clinical examination that showed an improvement at each consultation.

Lung function was assessed using spirometry. At visit 5, normal spirometry predominates with a percentage of $2.4 \%, 1.6 \%, 2.8 \%$ and $1.2 \%$ following the order of the age group. $0.4 \%$ of the patients have mild obstructive ventilatory dysfunction in categories 2,3 and 4 , respectively. $0.4 \%$ of the patients in group 4 had mild restrictive ventilatory dysfunction. In group 1, a percentage of $1.2 \%$ have mild mixed ventilatory dysfunction, and in group 2 , $0.4 \%$ have mild mixed ventilatory dysfunction. Moderate mixed ventilatory dysfunction was present in $0.4 \%$ of the patients in group 4 and similarly severe mixed ventilatory dysfunction was present in group 3 (Figure 6,7,8).

Overall, 12 (4.8\%) patients with asthma, COPD and ACO presented exacerbations in the year they were followed.

\section{Correlations between symptoms and spirometry and other results}

There was a significant correlation between symptoms and health status, assessed by 

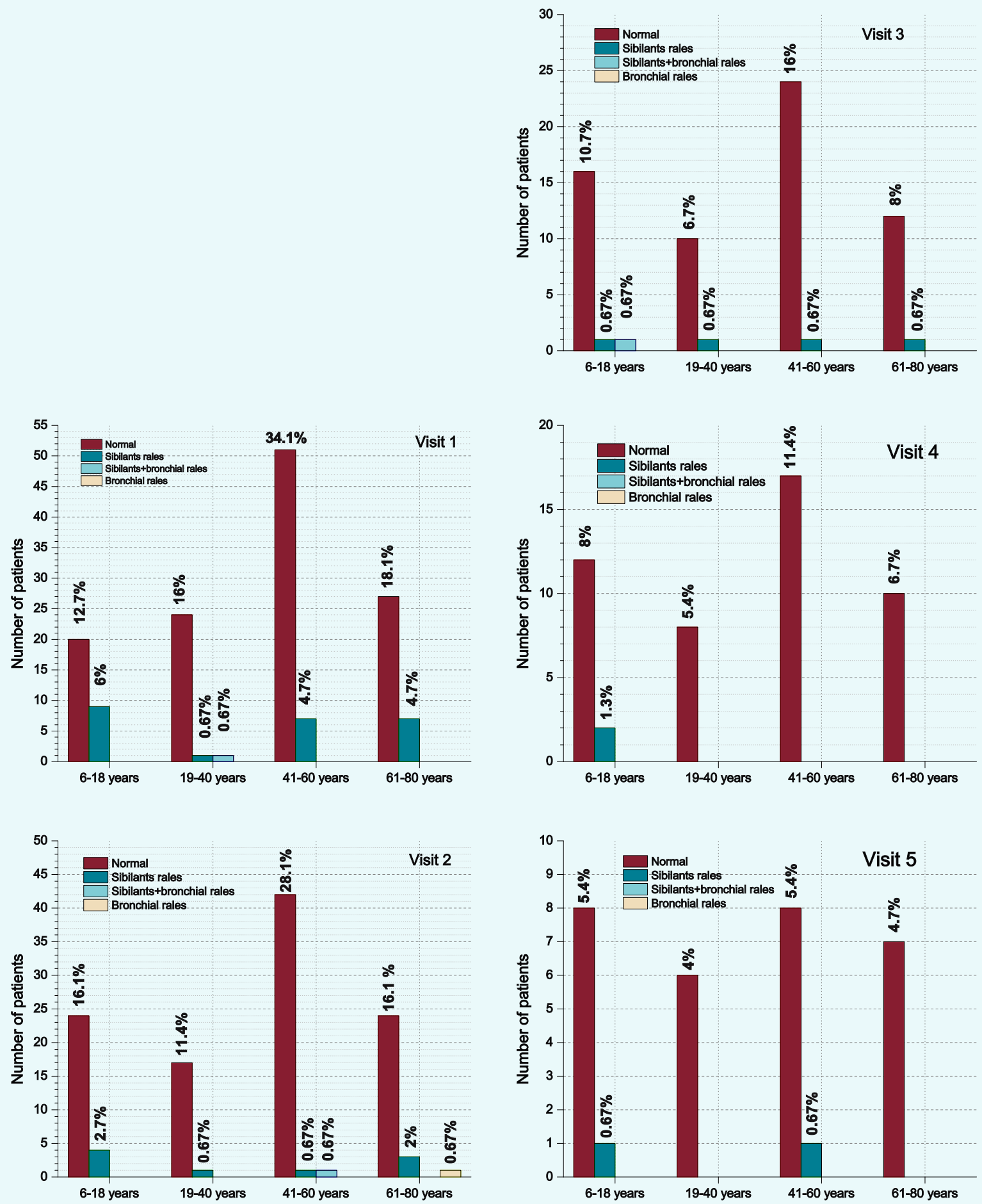

Figure 5. The prevalence of the evolution of the clinical examination in the total studied group 


\section{INTEF}
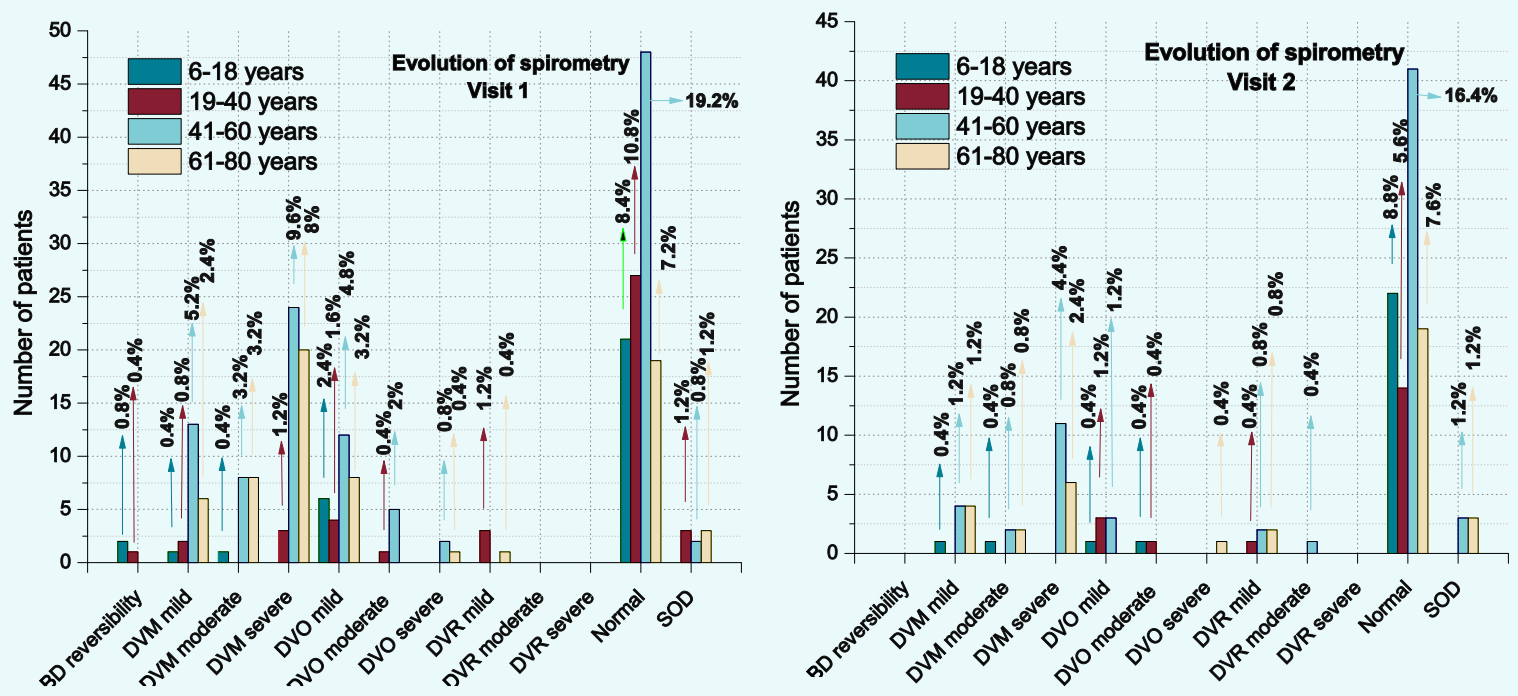

Figure 6. The prevalence of the evolution of spirometry at visit 1 and 2 in the total studied group
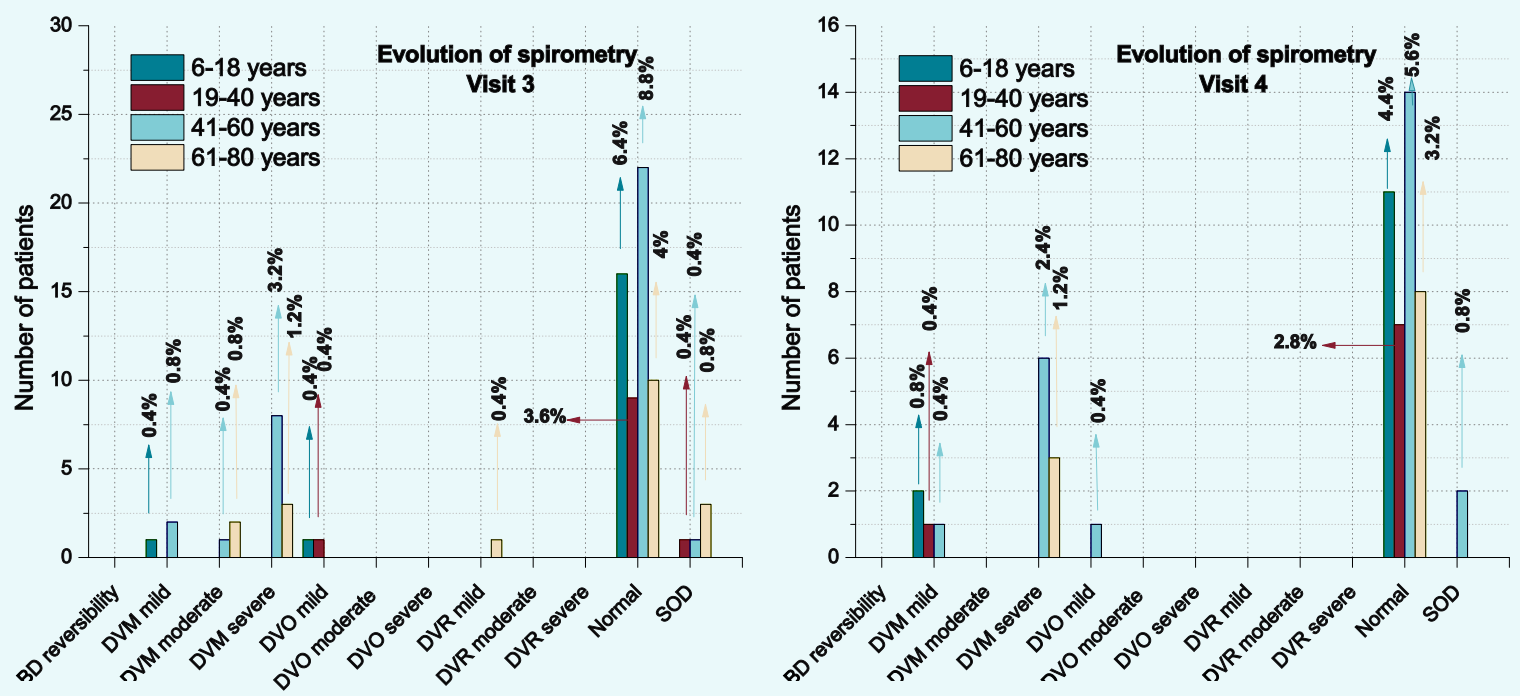

Figure 7. The prevalence of the evolution of spirometry at visit 3 and 4 in the total studied group 
CAT or ACT ( $p<0.001$ for all). Pulmonary function, assessed by spirometry and correlations with CAT / ACT were significant but weak $(p<0.001)$.

\section{Noncompliance factors identified in each age category}

During the analysed time interval, several noncompliance factors related to patients were identified (Figure 9).

a. Economic problems. Among the age groups with economic problems more vulnerable were those aged between 41$60(5.2 \%)$ and $61-80$ (4\%).

b. Antipathy towards medication. Young patients had the highest antipathy to medicines with a share of $6.4 \%$ in the $6-18$ age group followed by $4.4 \%$ in the $19-40$ age group.

c. The chronic nature of the disease. The chronicity of the disease is a noncompliance factor that determined a percentage of $8 \%$ in the category aged between 6-18, with a gradual decrease in the following categories, $4.8 \%, 2 \%, 1.2 \%$. Elderly patients who are used to the nature of the disease more readily accepted continuous treatment. It is the most difficult for young people to accept the fact that they have to administer the treatment daily and continuously.

d. Care for other family members. The first age group did not present this noncompliance problem. Instead, the highest value (8\%) was present in the 41 60 age group. Multiple socio-economic problems make people vulnerable and make them to worry about all family members, sometimes giving up on themselves to the detriment of others. Other strategies that patients said they used to save money on medication costs included buying cheaper generic prescription drugs. The groups aged between $19-40$ and $61-80$ had a similar percentage of $1.6 \%$ and $1.2 \%$.

e. Self-discontinuation. In all groups, selfdiscontinuation of treatment was found, but the highest percentage (8.4\%) was found in the group aged between 6-18. Children and adolescents are the most exposed to this noncompliance factor. They stopped the treatment believing that the problems were solved with the remission of symptoms. The categories aged between 19-40 and 41-60 followed with a percentage of $2.4 \%$ and $1.2 \%$, and those over 61 were the most compliant $(0.4 \%$ self-interruption was recorded), probably also due to complications and experience with chronic disease gained during life.

f. Cultural and religious problems. In all age groups a noncompliance regarding cultural and religious problems was found, small percentages in the category aged between 6-18 (0.8\%) and similar percentages in the other groups $(1.2 \%$, $2 \%, 08 \%)$. Religious patients are often suspicious of drug therapies.

g. Inhalation technique. In elderly patients, a defective technique predominated despite the doctors' explanations $13.6 \%$ in those aged between $41-60$ and $2.8 \%$ in those aged between 61-80). Aging probably makes them less able to understand all the explanations. A correct technique was observed in children and adolescents, which was also possible due to the involvement of parents in the administration of treatment to children and an increased attention of young people during the explanations.

h. Comorbidity. Elderly patients with comorbidities had the highest percentage 


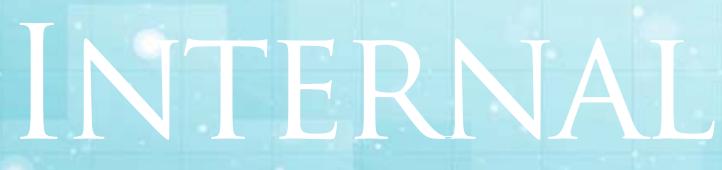

\section{Original Papers}

of noncompliance factor $(19.6 \%$ in those aged $41-60$ and $18.4 \%$ in those aged 61 $80)$. The other categories also had comorbidities, $2.4 \%$ in the group aged between $6-18$ and $18.4 \%$ in the group aged between 19-40.

j. Forgetting. This noncompliance factor was found in all age groups $(2.8 \%, 1.2 \%$, $2.4 \%, 3.2 \%$ following the order of the age categories). Improperly administered, a treatment loses its effectiveness and can have a negative impact on health which leads to additional consultations and the implementation of more complex treatments or hospitalization of the patient. Good reception of information and administration of treatment is beneficial to recovery.

\section{The group of compliant patients}

Demographic data on the distribution by sex indicate the predominance of males (2.8\%) in the first age category, and it is similar in group 2 with a percentage of $1.2 \%$. In groups 3 and 4 , females predominate $(3.2 \%$ and $1.6 \%$, respectively).

The distribution of patients according to the setting of origin showed that at the age of 6 18 and 19-40 the urban setting predominates, $3.2 \%$ patients and $1.6 \%$ patients, respectively. In the categories aged between 41-60 and 61-80, patients from rural setting predominate, $2.8 \%$, respectively
$1.6 \%$. Patient education is very important in understanding the disease and compliance with treatment (Figure 10).

Data on lifestyle, smoking status, atopic terrain are presented in Figure 11. Patients who benefited from prick skin testing for the most part, $8.6 \%$ were positive, respectively $2.8 \%$ patients were negative and $0.4 \%$ patients presented dermographism and could not be tested. Allergens are a factor of noncompliance in this group. Regarding the analysis of the smoking status, $12 \%$ of the compliant patients are non-smokers. Only $0.8 \%$ of the patients are former smokers. From this aspect it is revealed that smoking is not a factor that worsens the disease in these patients.

All compliant patients have asthma. Compliant patients who administered the treatment correctly obtained a control of the disease (well-controlled asthma ACT 8.8\%). Despite treatment, some continued to have partially controlled $(2.8 \%)$ or poorly controlled (1.6\%) asthma, but at a much lower percentage (Figure 12).

In this group of compliant patients, 14 patients had ACO (Figure 13). They had poor control of symptoms (ACT- very high) $0.4 \%$ of the patients with ACO aged between 19-40, and in the category aged between 41-60 $1.2 \%$ of the patients have uncontrolled asthma, respectively well controlled and $1.6 \%$ have partially controlled asthma. A 


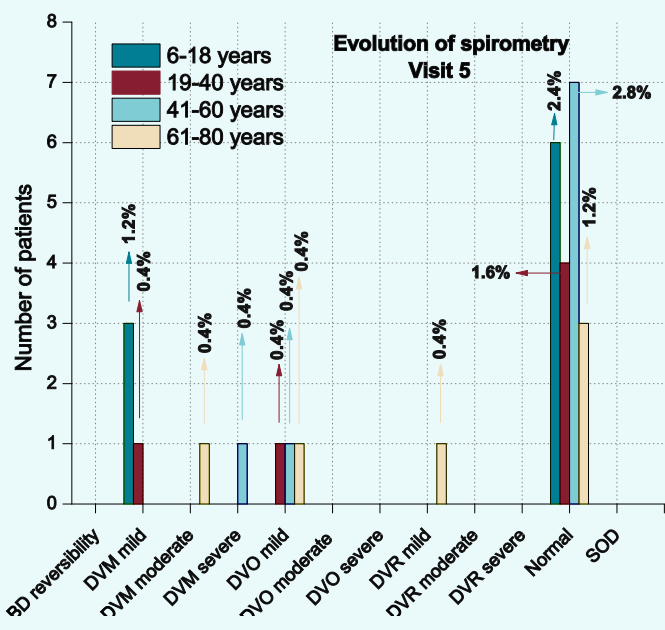

Figure 8. The prevalence of the evolution of spirometry at visit 5 in the total studied group

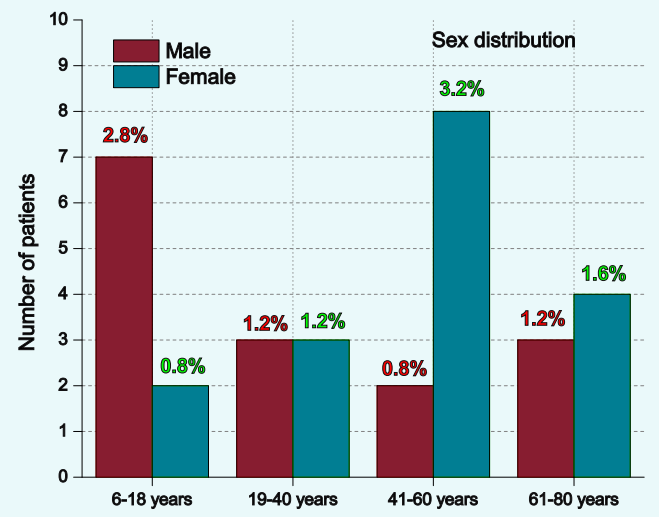

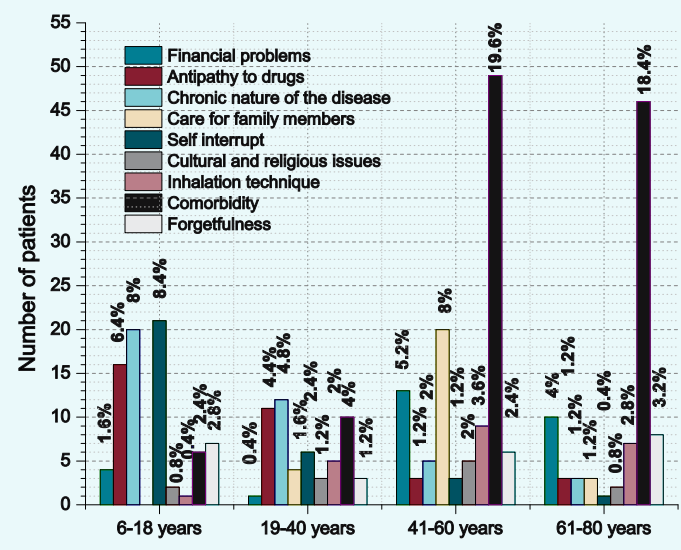

Figure 9. Noncompliance factors identified in each age category

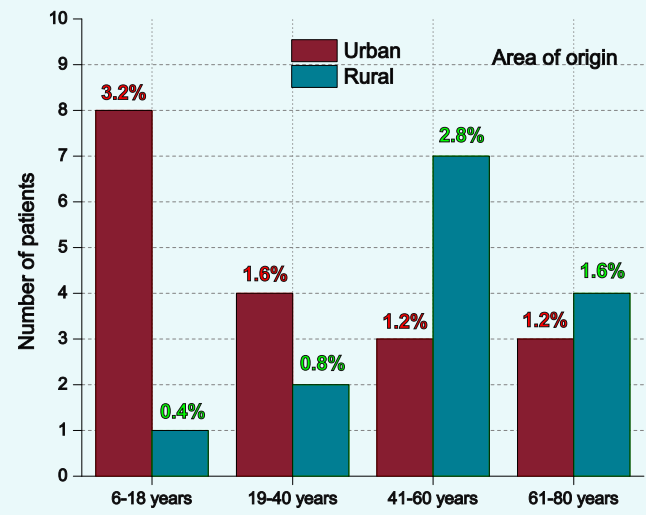

Figure 10. The distribution of compliant patients by sex and origin
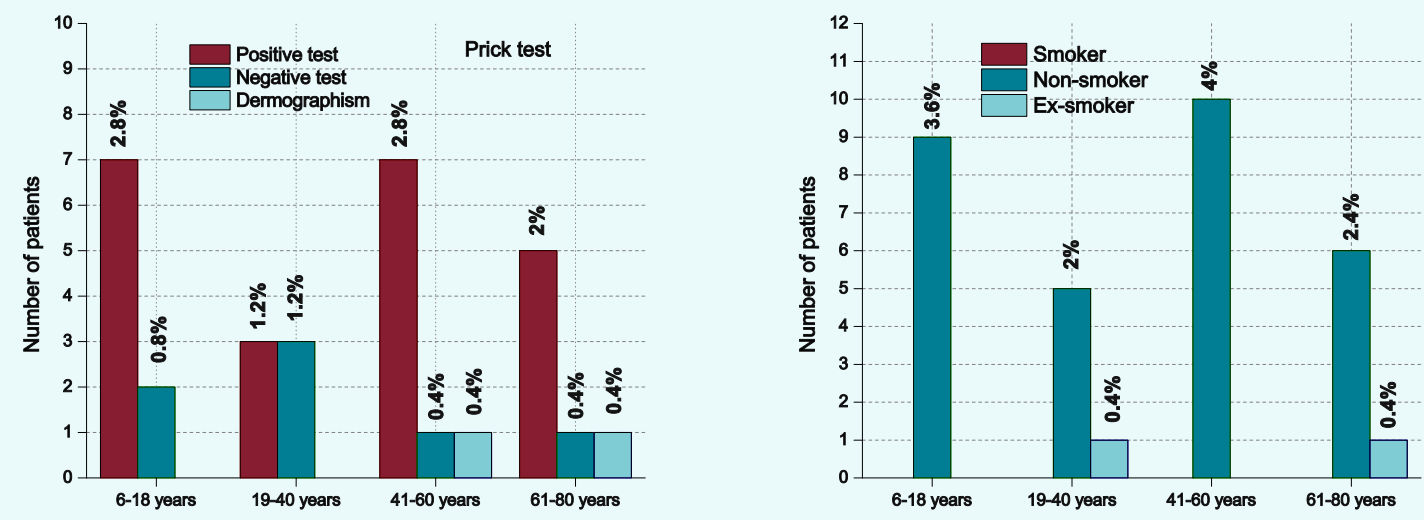

Figure 11. The prevalence of lifestyle factors Prick skin testing Smoker 


\section{INTEF}
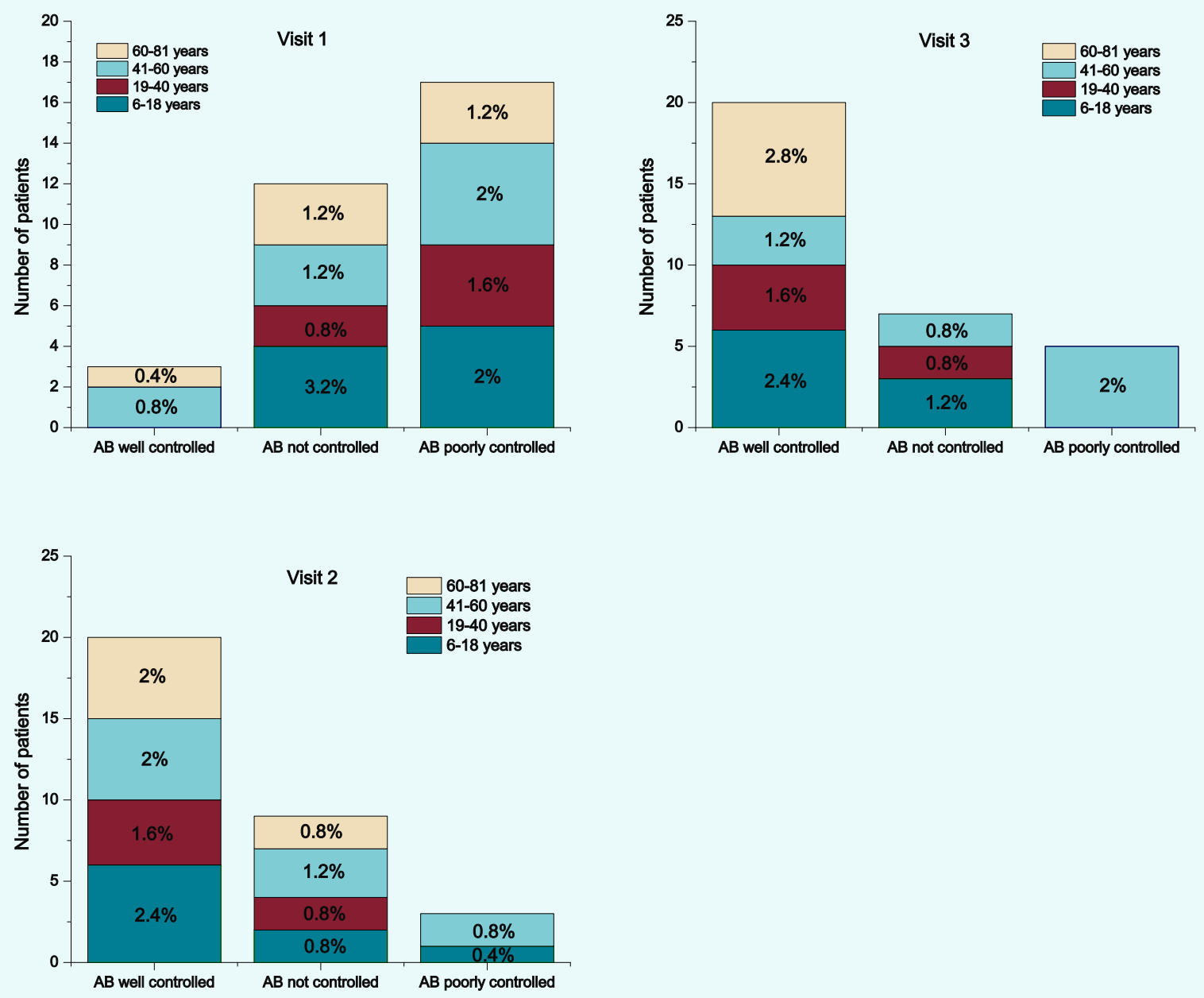

Figure 12. The prevalence of respiratory symptoms and their severity in asthmatic patients-according to the ACT questionnaire, visit 1, 2, 3 


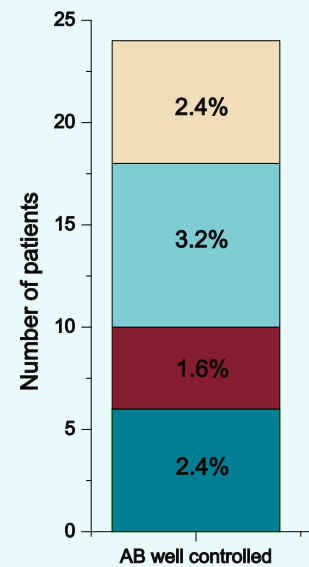

AB well controlled

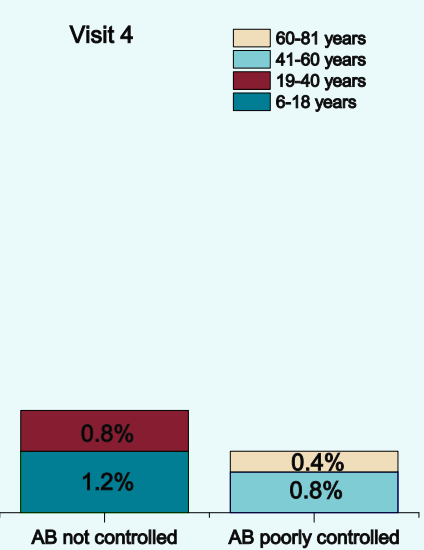

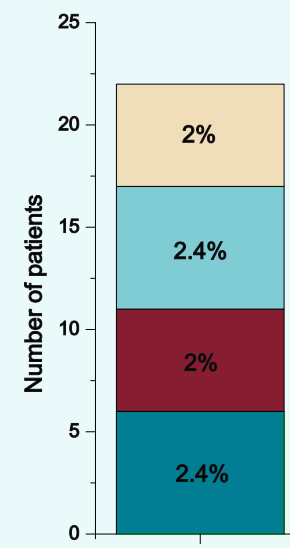

$A B$ well controlled

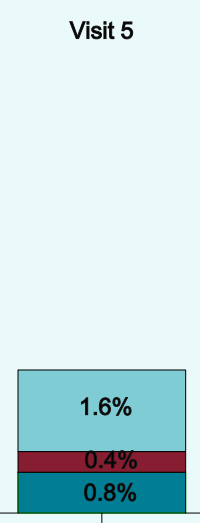

AB not controlled
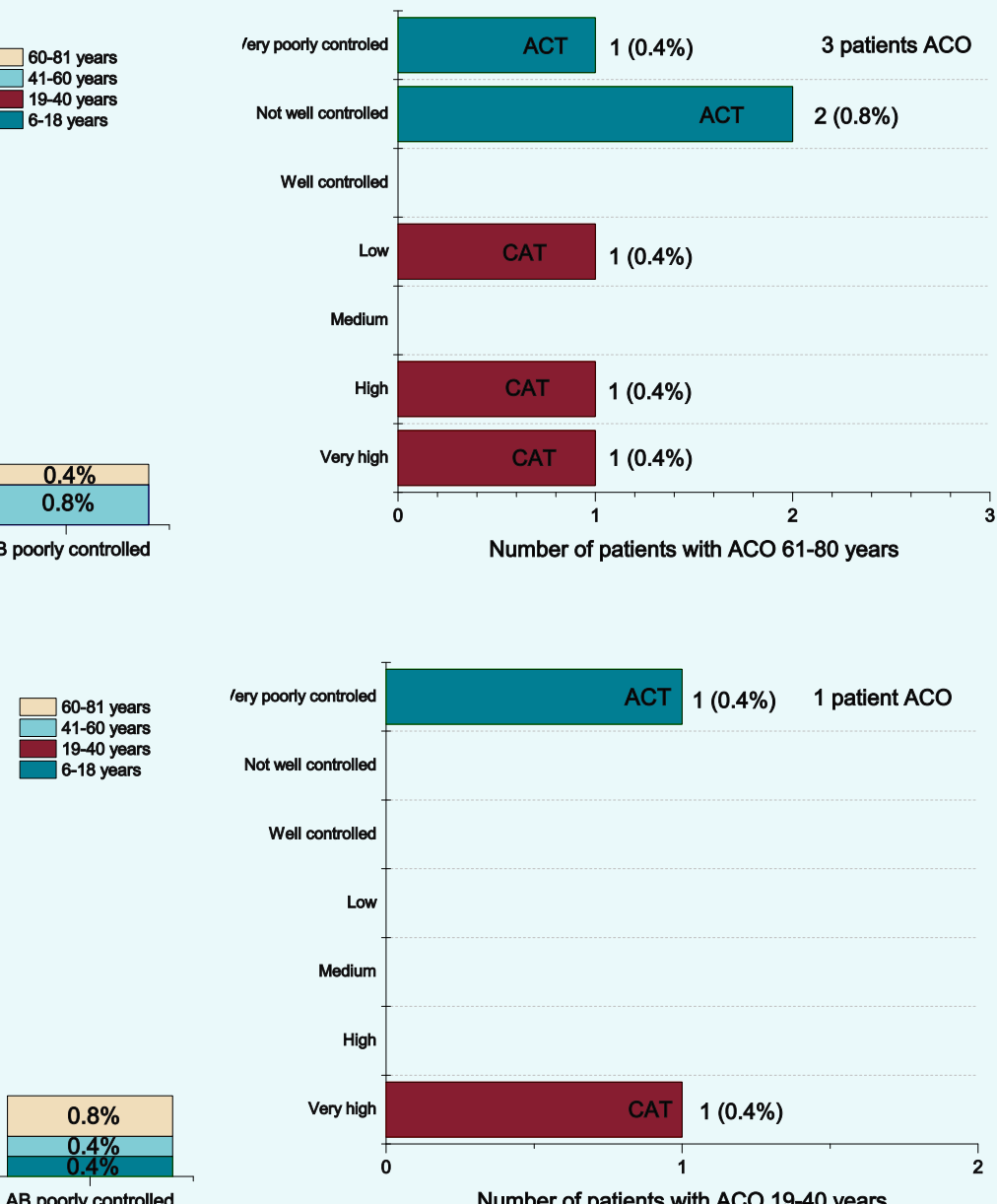

Figure 13. The prevalence of respiratory symptoms and their severity in patients with ACO (asthma-COPD overlap) syndrome 


\section{INTEF}
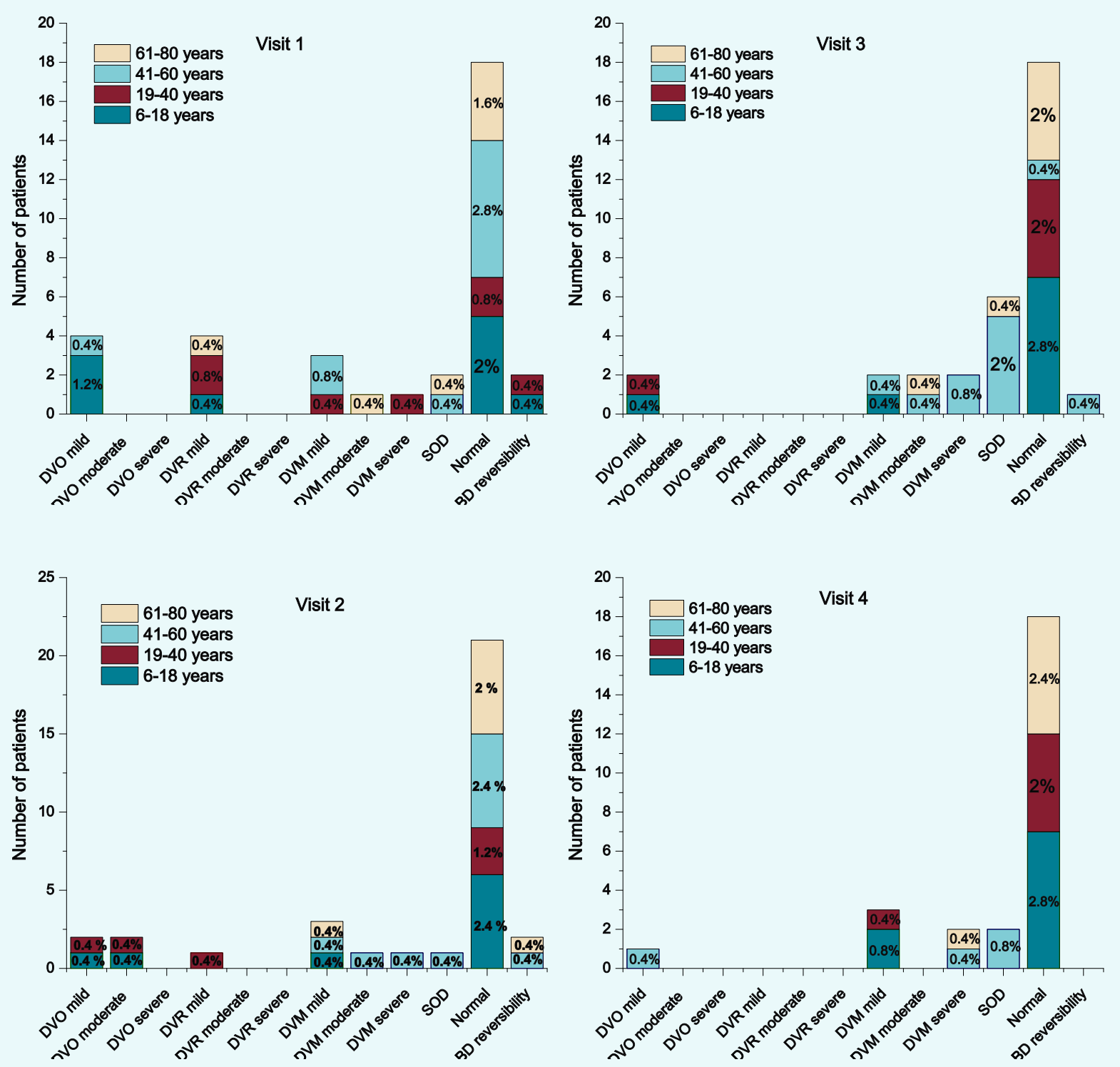

Figure 14. The prevalence of the evolution of spirometry at each visit in compliant patients, visit 1, 2, 3, 4 


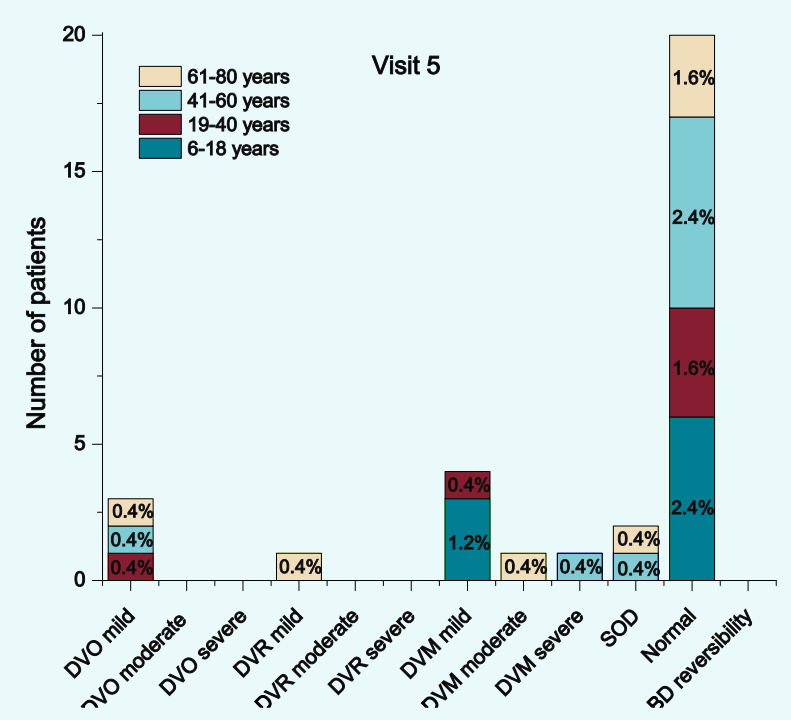

Figure 14. The prevalence of the evolution of spirometry at each visit in compliant patients, visit 5
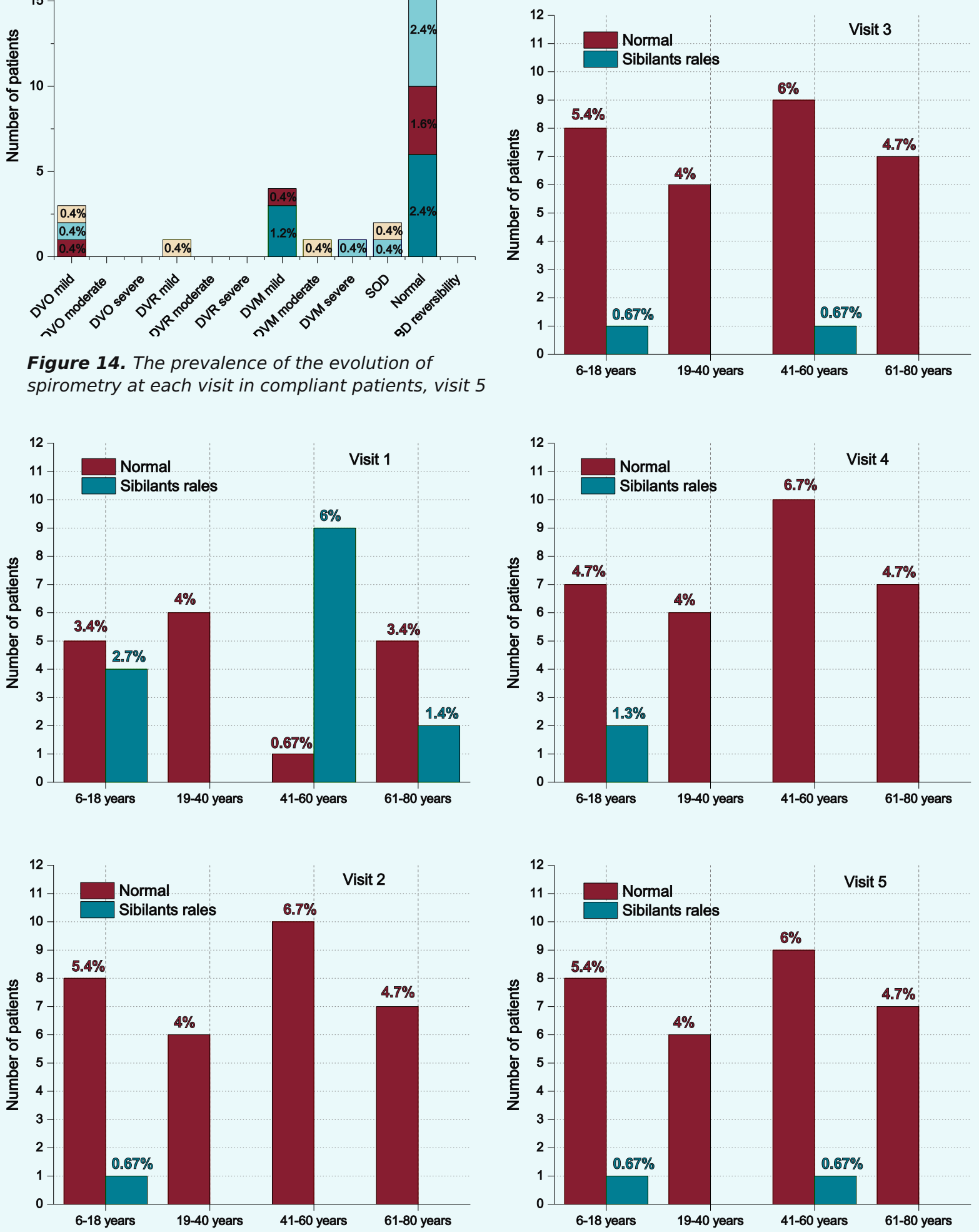

Figure 15. The prevalence of clinical examination at each visit in compliant patients 


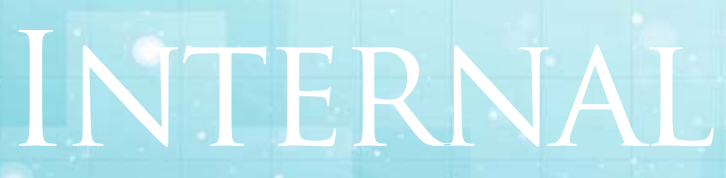

Original Papers

similar prevalence is also found in this category, $0.4 \%$ of the patients with low, high and very high CAT, and $2.8 \%$ patients had medium CAT. $1.2 \%$ of the patients aged between 61-80 have ACO; some have uncontrolled asthma $(0,4 \%)$ and partially controlled asthma $(0.8 \%)$; similar prevalence, of $0.4 \%$ in the CAT questionnaire with low, high and medium score was noted. The evaluation of the respiratory function performed with spirometry is presented in Figure 14. It had a very good evolution in compliant patients, with its normalization in most patients (8\%).

Very few patients had mild obstructive ventilatory dysfunction ( $1.2 \%$ ) and $0.4 \%$ mild restrictive ventilatory dysfunction, and mixed ventilatory dysfunction was found in $2.4 \%$ of patients. The clinical examination of the patients, presented in Fig. 15, was normal at most follow-up visits (20.1\%), but there were people who stethoacoustic pulmonary presented sibilant rallies (1.34\%).

\section{Discussions}

This randomized clinical study showed that the physician's involvement in improving patient compliance with treatment helps, but many patients with COPD and asthma continue to be absent from regular medical visits, and others have variable symptoms even after treatment. The percentage of noncompliant patients is high in all age groups. The results of the study indicated that $12.8 \%$ of the studied patients were compliant. Assessing respiratory compliance by the number of visits and symptomatology (using CAT questionnaires -a validated tool in COPD subjects that captures a wide range of questions on respiratory symptom intensity and ACT - Asthma Control Test) ${ }^{(5,20)}$, a low percentage of compliant patients in our cohort reported symptoms despite regular treatment. Future studies are needed to explore how noncompliance factors can be improved. Understanding the relationship between treatment compliance and respiratory symptoms has the potential to provide valuable information for the clinical management of COPD and asthma in a real world setting.

Consistent with other studies carried out on patients, our results indicate that compliance is multifactorial and lower than expected in patients with COPD and asthma. Factors that affect compliance are complex and involve psychological, social and medical issues, all of which can change patients' perceptions regarding the benefits of compliance with the recommended treatment regimen. Social and cultural factors such as socio-economic status, level of education, smoking and alcohol consumption, as well as faith problems directly affect treatment compliance $^{(21)}$. Weak compliance is common in 
all disease states, especially in the asymptomatic ones; about $50 \%$ of all patients do not get optimal clinical benefits from treatment due to poor medication compliance ${ }^{(22)}$.

Focusing on patient adherence in COPD, Bourbeau and Bartlett $^{(23)}$ agreed that adherence is multifactorial and highlighted that patients (health beliefs, cognitive abilities, self-efficacy, comorbidities, psychological profile, conscientiousness), doctors (method of administration, dosing regimen, polypharmacy, side effects) and society (patient-prescriber relationship, social assistance, access to medicines, device training, tracking) affect it. The interaction between patients and doctors is certainly crucial, with important mutual influences, while the role of society is an element that often authoritatively affects this interaction and is barely influenced by the wishes and needs of individual patients or individual doctors $^{(11)}$.

All of these findings serve to emphasize the need for standardized tools and guidance for physicians in assessing, promoting, and monitoring the compliance of asthma and COPD patients in daily clinical practice.

In the study, several different tools that refer to doctors were used to improve compliance with treatment (planned visits, good doctorpatient relationship, feedback at each visit revealing the triggering factors, explaining the inhalation technique, explaining the treatment regimen, explaining the importance of treatment administration and highlighting the side effects), and the results were low.

An indicator that could not be achieved is the education of the patients. Randomized studies indicate that educational initiatives especially when performed by physicians for patients - have a positive impact on health behaviours. Moreover, other studies have shown that patients interpret and evaluate medical advice based on their own beliefs regarding their disease and its treatment ${ }^{(21,24)}$. This suggests that non-adherence may arise from potentially erroneous beliefs about the nature of the disease (e.g., its severity, probable duration, causes and consequences) and the relative benefits and risks of the treatment ${ }^{(25,26)}$.

For example, many patients avoid taking prescribed medication due to misplaced concerns about potential side effects or because regular use is perceived as unnecessary ${ }^{(54)}$. Patients will be more likely to follow treatment advice if they perceive that this is the right approach for maintaining their health and if they have a clear understanding of the nature of the disease and the relative benefits and risks of treatment ${ }^{(21)}$. There is some evidence (a subgroup of 205 participants) that the exchange of feedback on compliance with the patients themselves can improve compliance ${ }^{(21,28)}$.

Patients who received feedback at the followup visit were significantly more compliant than those who did not $-60.2 \%$ compared to $40.4 \%$; and the proportion of correct use $80.6 \%$ vs $60.3 \%{ }^{(21)}$.

An important finding from our study was that compliance leads to decreased exacerbations; only $4.8 \%$ of the patients with asthma, COPD and ACO had exacerbations during the year they were followed. Balkrishnan et al. showed, in ICS users, a $40 \%$ decrease in the risk of an emergency department visit/hospitalization in adherent versus non-adherent elderly patients with chronic lung disease, including asthma $^{(29)}$.

Despite the heterogeneity between studies in terms of definitions of adherence and exacerbations of asthma, most high quality studies have consistently reported an 


\section{INTERNAI}

\section{Original Papers}

association between low adherence and an increased risk of severe asthma exacerbations in both adults and children ${ }^{(29)}$.

These findings show that other elements of compliance, such as social factors and institutional intervention regarding the cost of the treatment, should be explored, combined with the symptoms, in order to better understand and address the low level of compliance in patients with COPD and asthma.

Changing the complex health behaviour, such as increasing treatment compliance, is a difficult task and requires a multidisciplinary approach. Several studies exploring multimodal (pharmacological and behavioural) interventions ${ }^{(17.30)}$ show that more specific recommendations for increasing long-term compliance in people with chronic diseases and probably a change in the mentality of the doctors in order to properly understand the increase in compliance are needed to guide clinicians in current practice, thus improving healthrelated quality of life and reducing depression and anxiety in patients ${ }^{(18)}$.

Low compliance rates are a major challenge for the effective management of most chronic diseases, including asthma.

The characteristics of the regimen, such as dosing frequency and route of administration, can significantly contribute to noncompliance, but are not the only factors. Many patients choose not to use their medication as indicated because they feel it is useless or because they are concerned about the side effects.

Thus, an integrated approach is needed to facilitate the compliance that addresses the patient's motivation to follow treatment advice, as well as their ability to do so. In addition to ensuring that the regimen is adapted to the patient's lifestyle, it is necessary to provide patients with a clear justification for treatment that is consistent with their perceptions of the disease and that addresses any concerns about the adverse effects of its administration ${ }^{(21)}$.

In a study carried out on 400 patients, where $58 \%$ had primary or secondary education and $10 \%$ were illiterate, $38.5 \%$ regularly used aerosol therapy and the remaining $61.5 \%$ were noncompliant.

The main non-medicinal factors associated with poor compliance were: fear of adverse drug effects (18\%), higher cost of therapy $(10 \%)$, feeling of well-being after treatment (8\%) and patient negligence $(7 \%)$, anger about the condition or its treatment $(3 \%)$, forgetfulness (5\%) and attitudes towards health (5\%). In a study carried out on 246 patients, it was found that $61.5 \%$ do not observe asthma therapy.

There were 20 patients with higher education and all patients observed the therapy regularly. Patients who had a graduation 
diploma had a better compliance (78\%) with medication. Patients with secondary education had a $60 \%$ involvement rate, patients with primary education had a high involvement rate of $71.4 \%$, while illiterate patients had an involvement rate of $100 \%$. Other causes for not following the treatment are medication factors, which include difficulties with the inhaler, uncomfortable regimens (for example, multiple daily administrations or multiple medications), dislike of medication and distant pharmacies. A study by Johnson et al. found a suboptimal compliance with inhalation therapy in $63 \%$ of COPD patients ${ }^{(31)}$.

According to the study that used the TAI tool (specific for inhaled medicines), the result reveals that $49.4 \%$ of asthmatic patients were adherents to inhalations and $32.3 \%$ of them were intermediate followers of inhaled anti-asthmatic drugs. However, the prevalence of noncompliance was $18.3 \%{ }^{(32)}$.

Despite all the efforts made by the physician, it was noted that the patients also have a great influence on the compliance with the treatment. These results have been found in other studies as well. A study in which compliance was recorded by self-reporting ( $n$ $=95)$ and change in canister weight $(n=70)$ and compared with electronic records of the date and time of each inhaler operation showed that $70 \%$ of the patients self-reported using the inhaler as prescribed, while electronic records showed that only $15 \%$ of the patients actually used their inhalers.

It is also obvious that treatment adherence is often not optimal and patients' perceived (reported) compliance is considerably higher than their actual (recorded) compliance ${ }^{(21)}$. Moreover, the compliance defined by electronic monitoring has been up to $27 \%$ in people who received $100 \%$ prescription ${ }^{(33)}$. A study carried out on 276 asthma patients compared medication compliance and it found that patients had higher compliance with oral theophylline than with inhaled corticosteroids.

The same study also found that adolescent patients (aged between 12-17) were considerably less compliant than elderly patients (aged between 18-65) with inhaled medicines ( 80 vs. $73 \%$ for theophylline; 30 vs. $57 \%$ for inhaled corticosteroids) ${ }^{(21,34)}$, thing we cannot say for our study, as compliance according to age was approximately similar (3.6\% for the group aged between $6-18,2.4 \%$ for those aged $19-40,4 \%$ for the group aged between $41-60$ and $2.8 \%$ for the group aged between 61-80)

One of the main findings of our study is that the percentage of compliant patients is lower than other studies show. First, this result supports that compliance is not only influenced by physicians, but also by patients. The act of monitoring compliance itself can improve patient compliance. A study assessing patient's compliance with inhaled corticosteroids showed that when patients were not informed that medication use was being monitored, a significant difference was observed between actual and prescribed use ${ }^{(21,35)}$; the compliance of the patients who were not informed about the monitoring was $70 \%$.

Thus, the more complicated the dosing regimen is, the less compliant the patients ${ }^{(21,36)}$ (effective compliance with the inhalation doses of two, three and four times a day was $71 \%, 34 \%$ and $18 \%$ respectively ${ }^{(21,37)}$. For bronchodilators, some technical errors are relatively harmless, as the lack of clinical effect will frequently lead to an additional dose in patients ${ }^{(21,38)}$. Many patients find dry powder inhalers easier to use because no coordination between the device operating and inspiration is required ${ }^{(21,39)}$. 


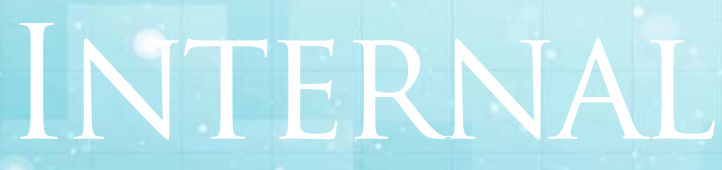

Original Papers

The impact of the type of inhaler on adhesion is controversial. A multicentre retrospective study based on a review of medical registries reported that COPD patients treated with a dry powder inhaler were less likely to have good adherence to medication compared to those treated with a metered-dose inhaler. However, other studies have shown different results in terms of the effect of the inhaler. In France, a survey carried out on 153 COPD patients identified that the strongest preference factors for inhalation devices were shape, dose counter, and reuse ${ }^{(40)}$.

According to the study conducted in Turkey in order to assess the effects of the correct use of inhalation devices, only $55.3 \%$ of the patients were able to correctly use the devices before training, but after training, the correct use rate increased to $83.7 \%{ }^{(32)}$.

A retrospective analysis evaluating 23,494 patients showed that users using multiple inhalers had a significantly higher discontinuation rate than users with a single inhaler ${ }^{(40)}$.

Unlike clinical trials, compliance is low and variable for the maintenance inhalation therapies in COPD. For example, a drug refill analysis performed on a batch of 5,504 patients with respiratory disease from a pharmacy database demonstrated that the rate of adherence to inhaled corticosteroid and long-acting $\beta$-agonist therapy was only $8.8 \%{ }^{(41,42)}$. In contrast, adherence was higher in a study carried on veterans, in which the regular use of long-acting beta-agonists and inhaled corticosteroids was 54 and 40\%, respectively ${ }^{(41,43)}$.

Another study that evaluated pharmacy records to estimate adherence to ICS, ipratropium bromide, and LABA over two consecutive six-month periods in 2,730 patients showed poor adherence, with $19.8 \%$ of the patients adhering to ICS, 30.6\% adherents to LABA and $25.6 \%$ to ipratropium bromide. Despite the fact that factors that drive adherence may differ depending on the class of drugs, some studies also indicate that patient's perception of the clinician's expertise is a relevant factor that is strongly associated with adherence to inhaled medication ${ }^{(40,44)}$. It is interesting that a cohort study that enrolled 13,178 hospitalized patients for COPD between 2007 and 2011 in Italy showed that adherence was higher in patients discharged from pulmonology departments ${ }^{(40)}$. Adherence to inhalation medication is weak and has great variability, ranging from $20 \%$ to over $60 \%$. Overall, it seems that compliance with inhalation medication may be related to the device in COPD patients and the amount of inhalers ${ }^{(40)}$.

This observation between noncompliance and the impact on patients emphasizes the importance of improving the compliance in patients with COPD and asthma. It might be that the factors related to the patient and the 
authorities are indeed the "missing link" in understanding noncompliance.

More information on noncompliance factors and clinical characteristics of patients would allow a more customized approach to their needs and living conditions. In this context, it seems reasonable to consider that noncompliance from the perspective of physicians is the only determinant factor of low compliance in patients with asthma and COPD.

The results of the studies summarized here suggest that, regardless of the status of the disease, patient education programs are needed to achieve increased compliance. The quality of the patient-physician interaction is a critical factor for therapy compliance.

A strong point of this study is the assessment of distant compliance and respiratory symptoms using validated questionnaires. The specific relationships between symptoms, noncompliance factors and other outcomes should be explored in more depth, being adjusted for noncompliance factors. The patient reported outcomes were collected via printed versions of the questionnaires.

There are no standardized tools for assessing compliance. In our study, compliance was measured only subjectively, by counting the medical visits of patients with COPD and asthma. However, even in this setting, the results indicate a real need for patient education to adequately assess and monitor compliance, and the introduction of validated and standardized questionnaires could be the easiest way to achieve this.

Although we have shown that compliance in terms of patients and institutions remains the most important in correcting noncompliance with treatment, special attention should be paid to making shared decisions between patient and doctor. Despite noncompliance, the medical staff does not make much effort or does not have enough time to understand the factors that interact with the patient's behaviour.

A study showed that 31 out of 83 patients (37\%) identified as nonadherent using records of prescriptions became adherents following a compliance interview, and that 27 patients $(90 \%)$ remained compliant at $12-18$ months after the discussion ${ }^{(45)}$. It is essential to determine the degree of patient behaviour that coincides with the prescribed treatment. Together with the understanding of the patient's behaviour, physicians can expand the types of explanations and solutions for compliance. Compliance is located at the end of a continuum in which the patient is involved in planning the treatment regimen in order to achieve therapeutic goals. Compliance with inhalation treatment remains a challenge. The family doctor could lead to its improvement.

\section{Conclusions}

Nowadays, it is surprising that the level of medication adherence in patients with COPD is very low, lower than the one recorded for other diseases ${ }^{(11,46)}$.

Despite an improved compliance from a medical perspective, most patients with asthma and COPD in the study did not regularly come to the medical visits, and some continued to have mild to severe symptoms. In both groups of patients (with asthma and COPD), the percentage of noncompliant patients was high. While the levels of noncompliance have been high in this cohort of asthma and COPD, they seem to be underestimated. Knowing that the lack of medication administration indicates the negative consequences on the health status, compliance factors related to the patient and institutions play a greater role in profiling patients than previously thought. In order to 


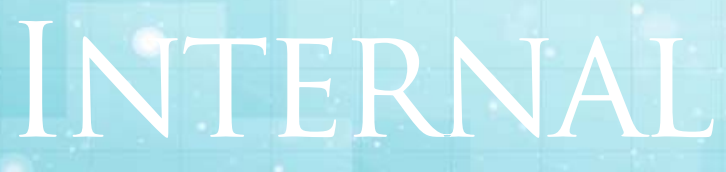

Original Papers

ensure long-term health benefits, appropriate tools are urgently needed to improve compliance and monitor noncompliance patterns and more actively promote the correction of noncompliance factors among patients with asthma and COPD.

All patients with asthma, COPD and ACO enjoyed advanced measures of explanations from health professionals, clinical care, complex monitoring and correction of known and unknown noncompliance factors.

The multiparametric analysis of the experience gathered in a period of 2 years (2017-2019) issued some conclusions:

The experience regarding the exploration of the noncompliance factors pursued in patients with asthma, COPD, ACO refers to 3 categories of factors, factors related to doctor, patient and regimen undertaken on 251 patients in a period of 2 years, which represents on average 125.5 patients / year. On the one hand it reflects the existence of an effective real concern in clinical practice, and on the other hand an assumption of the guiding principle of the compliance of patients with asthma, COPD, ACO. It should be noted that the group of compliant patients was able to overcome all noncompliance factors.

Noncompliance correction was indicated in order to solve exacerbations, symptoms or functional improvement of cases with asthma, COPD, ACO. A percentage of $12.8 \%$ of the patients had 5 visits. For the control of the diseases, the ACT (Asthma Control Test) questionnaire and the CAT questionnaire for COPD, and spirometry were used. The study shows that patient compliant on the long term can benefit of an improvement of symptoms (in the ACT questionnaire $8.8 \%$ had wellcontrolled asthma) and lung function (spirometry with normal values in 8.6\%). Lack of symptoms and correction of spirometric function indicate that compliance has led to a positive outcome in patients with asthma and ACO. Exacerbations are absent in the group of compliant patients.

In order to correct the compliance factors, we used the following strategies:

1. We planned the visits and followed the appointment schedule, and at each visit we provided the correct feedback on the current status in order to make improvements in terms of disease control and patients' expectations. The aim is to increase patients' confidence in medical services and healthcare professionals. The most compliant patients are those who receive permanent feedback. Every patient wants to know how his health status is evolving. The communication with the patient is very important when you want to keep a balance. Timely feedback can be an additional motivation for the patient. There were situations when the patient was going through a harder time at work or at home and forgot or did 
not make time to administer the inhaler. Thus, patient motivation is a key element when you want to maintain or improve the compliance. We used the doctor's communication skills with each individual patient and we maintained a good doctorpatient relationship.

2. We revealed the trigger factors (allergens, smoking) and recommended avoiding them. Once the patient avoids the trigger factors that lead to the occurrence of asthma, COPD or ACO symptoms, a good control of treatment is obtained. Regardless of the trigger, the aim was to control the symptoms and avoid exacerbations.

3. A percentage of $100 \%$ was included in the explanation of the treatment plan and we made a plan for a personalized treatment by mutual agreement. The importance of using the medication, even in the absence of symptoms, was discussed with the patient. Patients were informed about the status of the disease and the consequences of not observing the treatment. The main purpose of asthma treatment is to minimize the impact of the condition on daily life. If asthma, COPD, ACO are managed properly, we expect no symptoms during the day or at night and that patients do not feel limited when performing physical activities. Finally, we would like to minimize any side effects of the received treatment.

4. Inhalers are the main method of administering medicines used to treat asthma and COPD. However, they can only be effective if used correctly. Proper use of the inhaler releases the medicine into the lungs, where it can act to control symptoms. Improper use of an inhaler means that little or no medicine reaches the lungs. The inhalation technique was explained and showed to each patient. Subsequently, each patient received a demo device which they could practice the inhalation technique with in order to better master it. Our study showed that almost everyone can learn the proper technique of the inhaler with proper training and practice (only $8.22 \%$ of the patients who attended the second visit had a problem using the device, but this has also been corrected). In addition to all the interventions offered by the doctor, the patients received leaflets with informative content about their condition (asthma, COPD) and about the inhalation technique. Physicians' interventions led to improved patients' knowledge and compliance ( $p$ $=0.001$ ), even if the number of visits was decreasing, these interventions managed to give patients a state of control of symptoms.

Referring further to noncompliant patients, we noticed that $11.2 \%$ had economic problems preventing the procurement of treatment.

However, those who were able to overcome this barrier proved a high efficiency in controlling the symptoms $(p=0.001)$. However, a fairly significant number of noncompliant patients may be affected by poor savings. Assistance programs are needed for those who have difficulty in paying for medications. In the austerity conditions in our country, compliance factors in patients with asthma, COPD, ACO remains an aspiration, the possibilities of solving them being limited only to cases of worsening of the symptoms. Healthcare professionals should be aware of the compliance issues and take the opportunity to educate patients whenever they contact the healthcare system.

Even if efforts have been made to identify the noncompliance factors and correct them where possible, it can be inferred that noncompliant patients may also have a 


\section{INTERNAL}

\section{Original Papers}

problem related to the regimen or their own behaviour.

\section{References}

1. Chakrabarti S., What's in a name? Compliance, adherence and concordance in chronic psychiatric disorders. World J Psychiatr. 2014; 4(2): 30-36

2. Dinwiddie R, Müller WG., Adolescent treatment compliance in asthma. J $R$ Soc Med. 2002, 95(2): 6871.

3. Rafii F, Fatemi NS, Danielson E, Johansson CM, and Modanloo M, Compliance to treatment in patients with chronic illness: A concept exploration, Iran J Nurs Midwifery Res., 2014, 19(2): 159167

4. Bogart M, Stanford RH, Laliberté $F$ et al Medication adherence and persistence in chronic obstructive pulmonary disease patients receiving triple therapy in a USA commercially insured population. Int J Chron Obstruct Pulmon Dis. 2019; 14: 343352

5. Global Initiative for Asthma (GINA): Global strategy for asthma management and prevention. Update 2019 and Online Appendix. Available at http:// www.ginasthma.org.

6. Accordini S, Corsico AG, Braggion M, et al, The cost of persistent asthma in Europe: an international population-based study in adults. Int Arch Allergy Immunol. 2013;160:93101.

7. Nunes C, Pereira AM, Morais-Almeida M. Asthma costs and social impact. Asthma Res Pract. 2017;3:1

8. Cisternas MG, Blanc $P D$, Yen $I H$, et al, $A$ comprehensive study of the direct and indirect costs of adult asthma, J Allergy Clin Immunol. 2003;111:12128.

9. National Center for Chronic Disease Prevention and Health Promotion, Division of Population Health, https://www.cdc.gov/copd/infographics/copdcosts.html, reviewed: February 21, 2018

10. Bender BG., Rand C. Medication non-adherence and asthma treatment cost Curr Opin Allergy Clin Immunol. 2004;4(3):191-5

11. Rogliani P, Ora J, Puxeddu E, Matera MG, Cazzola M, Adherence to COPD treatment: Myth and reality, Respiratory Medicine, 2017, 129, 117-123
12. Mãgureanu I.L., Furtunescu F - Importanţa determinãrii prevalenţei BPOC, pneumologia.eu/ download-312.htm

13. Mihãlţan F, Daramus I, Paunescu B, Nemes $R$, Farcasanu D. Prevalence of Chronic Obstructive Pulmonary Disease (COPD) in Romania, 2012, Chest 142(4_MeetingAbstracts):658A

14. Mihãlţan F, Ulmeanu R, Nemeş R, Nedelcu R, Chronic obstructive pulmonary disease day a traditional strategy of the Romanian Society of Pneumology, Pneumologia 2020, Volume 68: Issue 4

15. Nicolaescu O-Astmul bronşic, Pneumologie [1 mai 201330 aprilie 2014]

16. Program iniţiat de Societatea Românã de Pneumologie şi implementat de S.C. Totem Communication SRL https://program-inspiro.ro/

17. Mihaltan F, Adir Y, Antczak A et al., Importance of the relationship between symptoms and self-reported physical activity level in stable COPD based on the results from the SPACE study, Respiratory Research, 2019, 20, 89

18. National Asthma Education and Prevention Program Expert Panel Report 3: Guidelines for the Diagnosis and Management of Asthma Full Report, Clinical Practice Guidelines, 2007, 07-4051

19. Global Initiative for Chronic Obstructive Lung Disease http://goldcopd.org/wp-content/ uploads/2017/11/GOLD-2018-v6.0-FINAL-revised-20Nov_WMS.pdf

20. Jones JW, Harding G, Berry P et al, Development and first validation of the COPD assessment test. Eur RespirJ. 2009;34(3):64854

21. Cochrane GM, Horne R, Chanez P; Compliance in asthma, Respiratory Medicine, 1999, 93, 763-769

22. Gold DT, McClung B Approaches to patient education: emphasizing the long-term value of compliance and persistence Am J Med 2006;119(4 Suppl 1):S32-7.

23. Bourbeau J., Bartlett S.J., Patient adherence in COPD, Thorax, 63 (9) (2008), pp. 831-838

24. Leventhal H, Diefenbach $M$, Leventhal EA. IIIness 
cognition: using common sense to understand treatment adherence and affect cognition interactions. Cognitive Ther Res 1992; 16: 143-163.

25. Horne R, Weinman J, Hankins M. The Beliefs about Medicines Questionnaire (BMQ): the development and evaluation of a new method for assessing cognitive representations of medication. Psychol Health 1999; 14: I-24.

26. Petrie KJ, Weinman J, Sharpe N, Buckley J. Predicting return to work and functioning following myocardial infarction: the role of the patient's view of their illness. $B$ Med J 1996; 312: 1191-1194.

27. Horne R, Weinman J. Patients' beliefs about prescribed medicines and their role in adherence to reatment in chronic physical illness. J Psychosom Res, 1999;47(6):555-67.

28. Nides MA, Tashkin DP, Simmons MS et al. Improving inhaler adherence in a clinical trial through the use of the Nebulizer Chronolog. Chest 1993; 104: 501-507

29. Engelkes M., Janssens HM, Johan C. de Jongste et al Medication adherence and the risk of severe asthma exacerbations: a systematic review, European Respiratory Journal 2015 45: 396-407

30. Watz H, Troosters T, Beeh KM et al., ACTIVATE: the effect of aclidinium/formoterol on hyperinflation, exercise capacity, and physical activity in patients with COPD. Int J Chron Obstruct Pulmon Dis. 2017;12:254558.

31. Gaude G, Hattiholi J, Chaudhury A, Poor compliance to inhaler therapy in bronchial asthma patients a prospective study in general population, Science Journal of Clinical Medicine 1.2014; 3(1): 4-9

32. Ayele A.A., Tegegn H.G., Non adherence to inhalational medications and associated factors among patients with asthma in a referral hospital in Ethiopia, using validated tool TAl Asthma Research and Practice, 2017 volume 3, Article number: 7

33. McDonald V.M., Yorke J., Adherence in severe asthma: time to get it right, European Respiratory Journal 201750: 1702191

34. Kelloway JS, Wyatt RA, Adlis SA. Comparison of patients' compliance with prescribed oral and inhaled asthma medications. Arch Zntern Med 1994; 154: 13491352

35. Yeung $M$, O'Connor SA, Parry DT, Cochrane GM.
Compliance with prescribed drug therapy in asthma. Respir Med 1994; 88: 31-35

36. Eisen SA, Miller DK, Woodward RS, Spitznagel E, Przybeck TR. The effect of prescribed daily dose frequency on patient medication compliance. Arch Zntern Med 1990; 150: 1881-1884

37. Coutts JAP, Gibson NA, Paton JY. Measuring compliance with inhaled medication in asthma. Arch Dis Child 1992; 67: 332-333.

38. Chapman KR, Love L, Brubaker H. A comparison of breath-actuated and conventional metered-dose inhaler inhalation techniques in elderly subjects. Chest 1993; 104: 1332-1337.

39. Malton A, Sumby BS, Dandiker Y. A comparison of invitro drug delivery from salbutamol Diskus and terbutaline Turbohaler inhalers. J Pharm Med 1996; 6: 3548

40. López-Campos JL Quintana G E, Carrasco H L, Status of and strategies for improving adherence to COPD treatment, 2019,14,15031515

41. Blackstock FC, ZuWallack R, Nici L, Lareau SC. Why Don't Our Patients with Chronic Obstructive Pulmonary Disease Listen to Us? The Enigma of Nonadherence, 2015, 13, 3

42. Bender BG, Pedan A, Varasteh LT. Adherence and persistence with fluticasone propionate/salmeterol combination therapy. J Allergy Clin Immunol 2006;118:899904.

43. Cecere LM, Slatore CG, Uman JE et al., Adherence to long-acting inhaled therapies among patients with chronic obstructive pulmonary disease (COPD). COPD 2012;9:251258.

44. Cecere LM, Slatore CG, Uman JE, et al. Adherence to long-acting inhaled therapies among patients with chronic obstructive pulmonary disease (COPD). COPD. 2012;9(3):251258.

45. Lindsay JT, Heaney LG, Nonadherence in difficult asthma facts, myths, and a time to act, Patient Prefer Adherence. 2013; 7: 329336

46. Rolnick S.J., Pawloski P.A., Hedblom B.D., Asche S.E., Bruzek R.J., Patient characteristics associated with medication adherence, Clin. Med. Res., 2013, 11 (2),5465 